Separtment

of Transportation

National Highway

Traffic Safety

Administration

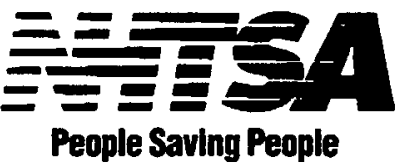

DOT HS 808381

March 1996

Final Report

\title{
Effectiveness of Passive Alcohol Sensors
}


This publication is distributed by the U.S. Department of Transportation, National Highway Traffic Safety Administration, in the interest of information exchange. The opinions, findings and conclusions expressed in this publication are those of the author(s) and not necessarily those of the Department of Transportation or the National Highway Traffic Safety Administration. The United States Government assumes no liability for its contents or use thereof. If trade or manufacturers' name or products are mentioned, it is because they are considered essential to the object of the publication and should not be construed as an endorsement. The United States Government does not endorse products or manufacturers. 


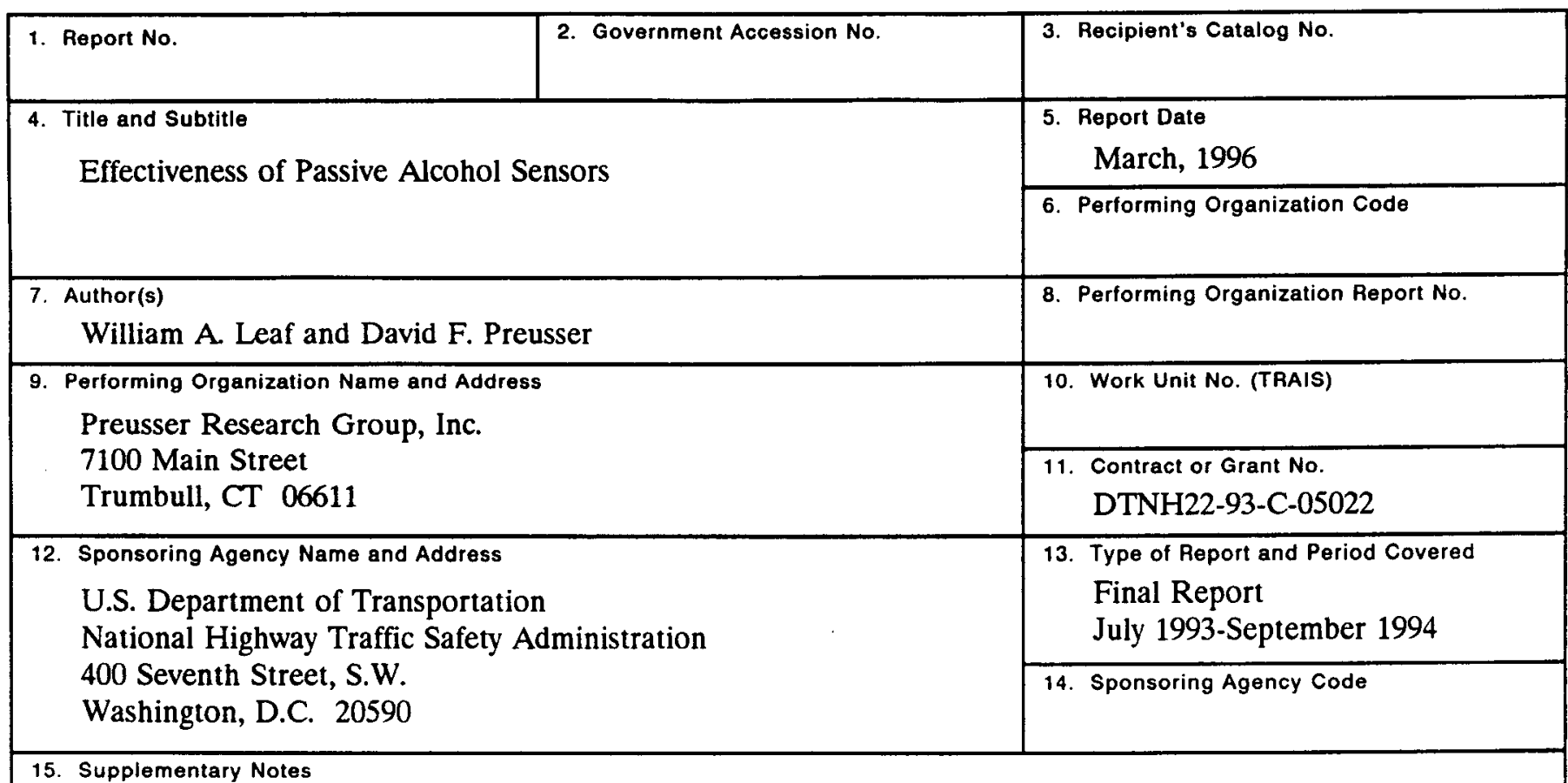

Dr. Linda A. Cosgrove served as the NHTSA Contracting Officer's Technical Representative for the study.

16. Abstract

The purpose of this study was to evaluate the effectiveness of passive alcohol sensors for youth alcohol enforcement conducted as part of normal or typical police operations. Three municipal police departments of 100 or more sworn officers in three states with zero tolerance legislation used each of three commercially-available passive alcohol sensors for two month periods in duty assignments likely to encounter youth and DWI enforcement opportunities. Applications of the passive sensors were logged, and after each test period each officer provided written evaluations and participated in debriefing discussions. Data for several years preceding the test period and the test period for underage liquor law violations and underage DWI arrests and convictions were also examined.

Devices were used more than 1,100 times in normal traffic stops, one sobriety checkpoint, youth encounters, and domestic disturbances. Overall judgments were positive by the officers and their departments, but there were differences between situations and devices. Officers were concerned about officer safety when using the devices for initial screening in normal traffic stops. Comments and suggestions specific to each device were cataloged. Few of the uses of the passive sensors led to alcohol-related arrests, and the underage liquor law and DWI data did not show changes over the test period compared to preceding periods. The discussion noted different requirements for portable alcohol sensors for low-BAC (youth, zero tolerance) and DWI (adult, .08\% or .10\%) enforcement and for tests without and with active subject participation.

\begin{tabular}{|c|c|c|c|c|}
\hline $\begin{array}{l}\text { 17. Key Words } \\
\text { Passive Sensors } \\
\text { Alcohol Test } \\
\text { DWI } \\
\text { DWID }\end{array}$ & $\begin{array}{l}\text { Impaired Driving } \\
\text { Adjudication } \\
\text { Enforcement }\end{array}$ & $\begin{array}{l}\text { 18. Distributio } \\
\text { Docume } \\
\text { National } \\
\text { Springfie }\end{array}$ & $\begin{array}{l}\text { ilable through } \\
\text { cal Information } \\
22161\end{array}$ & \\
\hline $\begin{array}{l}\text { 19. Security Classif. (of this report) } \\
\text { Unclassified }\end{array}$ & \multicolumn{2}{|c|}{$\begin{array}{l}\text { 20. Security Classif. (of this page) } \\
\text { Unclassified }\end{array}$} & 21. No. of Pages & 22. Price \\
\hline
\end{tabular}


TECHNICAL SUMMARY

\begin{tabular}{l|l}
\hline CONTAACTOR & CONTRACT NUMBER \\
Preusser Research Group, Inc. & DTNH22-93-C-05022 \\
\hline REPORT TITLE & REPORT DATE \\
Effectiveness of Passive Alcohol Sensors & March, 1996 \\
\hline
\end{tabular}

\section{Background}

All fifty states and the District of Columbia have laws banning the sale of alcohol to persons under the age of 21 . Nonetheless, underage persons continue to drink and drive and become involved in alcohol related crashes.

Underage crash involved drinking drivers are often found to have lower blood alcohol concentrations (BACs) than older drinking drivers. The combination of young age, inexperience with driving, and inexperience with drinking likely all contribute to this elevated crash risk after consuming even small or moderate amounts of alcohol. For this reason, several states have adopted zero tolerance or low BAC laws for underage drivers. These laws establish BAC limits for underage drivers which are, typically, far below the limits set for older drivers.

Most of the zero tolerance laws are relatively new. Little is known about effective enforcement strategies. However, it is known that the overall number of impaired driving arrests for underage drivers is much lower than would be expected given their incidence in alcohol related crashes. One possible technology for enhancing impaired driving enforcement, and zero tolerance enforcement, for young drivers is the passive alcohol sensor.

Passive sensors can assist the officer by testing the air surrounding a driver for the presence of alcohol. If alcohol is detected, it may be from the exhaled breath of the driver or from some other source such as a drinking passenger, an open container or alcohol based hair spray. Such devices do not, by themselves, provide probable cause for an alcohol related arrest. However, they may provide reasonable suspicion to proceed with an alcohol investigation.

Previous studies have tested passive sensors in the laboratory, at sobriety checkpoints and in controlled patrol operations. In general, results have indicated that the sensors are able to discriminate the presence and absence of alcohol and have been able to provide approximate driver BAC levels. Using passive sensors, officers have been able to detain fewer drivers below 
some target BAC threshold and arrest more drivers at or above the threshold. These studies have emphasized adult thresholds in the range of $.05 \%$ to $.10 \%$ BAC. The specific applicability of passive sensors to youth alcohol enforcement is unknown.

\section{Objective}

The objective of this study was to evaluate the effectiveness of passive alcohol sensors for youth alcohol enforcement conducted as part of normal or typical police operations.

\section{Method}

Three municipal police agencies located in states with zero tolerance legislation participated in this study: Chandler, Arizona; Hamilton Township, New Jersey; and Murfreesboro, Tennessee. Each was a mid-sized department with a sworn strength of approximately 100 or more officers. Each served a community which was expected to have a substantial number of young drivers.

At the time this study began, three manufacturers were marketing passive sensors for use by police agencies. A minimum of six of each of the following units were obtained: Sniffer P.A.S. III from Public Service Technologies; PBA 3000 from Life Loc; and Mark X Alcohol Checker from Guth Laboratories. Each participating police agency worked with each type of unit for approximately two months. Each two month period began with training and ended with an officer debriefing. Participating officers worked patrol (13), traffic (4), or motorcycle (4) or were assigned to youth related units (7). Primary data sources were the officer debriefings, officer maintained logs of sensor deployments, and youth alcohol arrest/adjudication statistics.

This study differs from previous research in that the emphasis was on the integration of these devices into normal or typical police operations. Participating officers were in control of how and when they used the devices. Thus, this study involved the basic acceptance of the devices on their own merits as well as, once used, how effective they were.

\section{Results}

Participating officers deployed passive sensors approximately 1,100 times in an enforcement context during the course of this study (excluding training and demonstrations). Most deployments were for drivers ( 83 percent) contacted as part of routine patrol or traffic operations. Approximately 27 percent of all deployments resulted in a positive BAC reading; approximately 16 percent of all tested subjects were charged with an alcohol related violation. An alcohol charge, particularly for sensor readings ranging from $.01 \%$ to $.09 \% \mathrm{BAC}$, was more likely for persons under the age of 21 than for persons over the age of 21.

The number of sensor deployments declined substantially over time. Approximately half of all deployments occurred during the first two month test period; one third during the second; and one sixth during the third. The decline in sensor use occurred in all three participating police agencies. 
Concern about the safety of officers while working alone during routine traffic stops was a common theme in the officer debriefings. During the initial moments of a motorist contact, officers need to have both hands free and all of their attention devoted to assessing the situation. Operation of the sensor demands some attention; the test itself brings the officer closer to the motorist than would otherwise be the case, and the PBA 3000 in particular occupies at least one hand. Typically, officers left the sensor in their vehicle for the initial traffic stop and then deployed the sensor later as part of their investigation. Also, some officers felt that passive sensors too often provided low or zero readings when alcohol was, in fact, present, and officer concerns over adjudication for sensor involved cases seemed to grow, not diminish, over time.

In the test jurisdictions, overall numbers of under 21 alcohol related arrests did not increase significantly during the period of this study, though such increases would not necessarily be expected given that each agency typically only had six sensors for their 100 or more sworn officers.

Participating officers did feel that passive sensors were particularly useful for: 1) sobriety checkpoints; 2) crash investigations after the location had been secured and treatment had been obtained for the injured; 3) underage liquor law and zero tolerance violations; and 4) school and community presentations.

\section{Conclusion}

Passive alcohol sensors were developed for the purpose of "passively" determining whether a driver's BAC was above or below some limit, typically .10\%. Accuracy in BAC estimation, particularly for BACs near the limit, was at a premium. Achieving accuracy required that the device be held at just the right distance from the driver capturing just the right amount of air from exhaled breath typically when the driver was speaking. For enforcement of zero tolerance or other low-BAC laws, requirements for passive alcohol sensors are somewhat different: Maximum ability to detect the presence of any alcohol and quick recycle time, and less emphasis on accurate measurement of BAC levels. Within the realm of portable alcohol sensors, a third use, that of accurate BAC measurement for cooperating subjects, exists and is currently addressed by PBTs.

Overall results from the present study can best be summarized as equivocal. Yes, the sensors were used and were seen as useful by the participating agencies. But no, they did not provide an "order of magnitude" improvement in the ability of patrol officers to detect and charge zero tolerance violations, and they were also awkward to use in routine traffic stop situations. In fact, use of the sensors declined over the period of the study in each of the three departments. Sensors to meet all these needs would be passive not only from the point of view of the suspect, but from the point of view of the officer. They might also have a mode designed specifically to sample large volumes of air to detect the presence of any alcohol (e.g., for zero tolerance violations) as well as, or in addition to, their mode of sampling measured quantities of air to accurately determine BAC level. 


\section{ACKNOWLEDGEMENTS}

The study could not have been performed without the enthusiastic cooperation of the three police departments who served as test sites: Chandler (AZ) Police Department, Hamilton Township (NJ) Police Department, and Murfreesboro (TN) Police Department. We especially thank the on-site coordinators of the project and the officers who used the passive sensors in their normal duties. We thank also the courts and records personnel in each jurisdiction who provided us with historical arrest and adjudication information.

Dr. Linda Cosgrove served as the NHTSA Contracting Officer's Technical Representative for the study. We appreciate the guidance and support she provided. 


\section{Table of Contents}

$\underline{\text { Page }}$

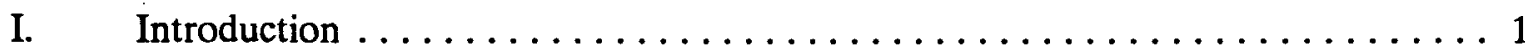

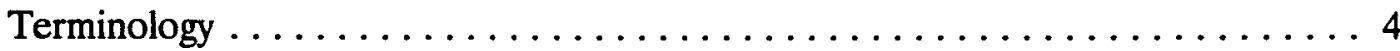

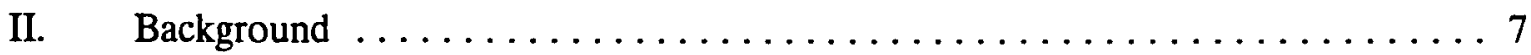

Laboratory Tests of Passive Alcohol Sensors $\ldots \ldots \ldots \ldots \ldots \ldots \ldots \ldots$

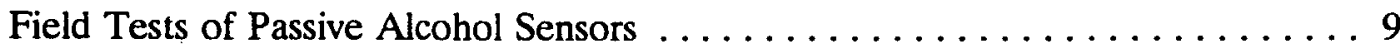

Summary . . . . . . . . . . . . . . . . . . . . . . . . . . 14

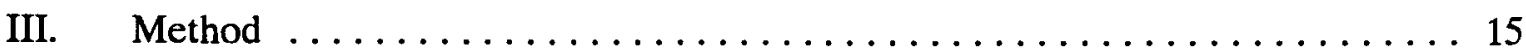

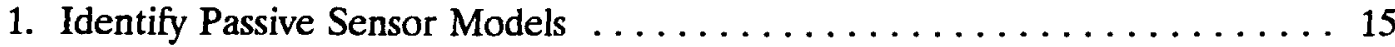

2. Identify Sites . . . . . . . . . . . . . . . . . . . . . . . . . . . . . . 19

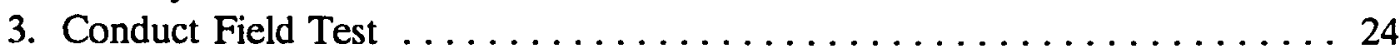

4. Collect Background Information and Statistics .............. 26

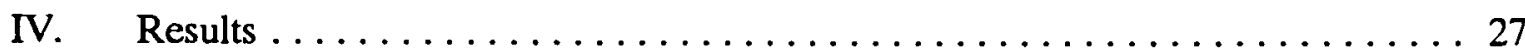

Use of Passive Alcohol Sensors by Officers . . . . . . . . . . . . . . . . . 27

Underage DWI Arrest Records ....................... 36

Underage Liquor Law Violations $\ldots \ldots \ldots \ldots \ldots \ldots \ldots \ldots \ldots \ldots \ldots \ldots$

Subjective Reactions from Study Participants $\ldots \ldots \ldots \ldots \ldots \ldots \ldots \ldots$

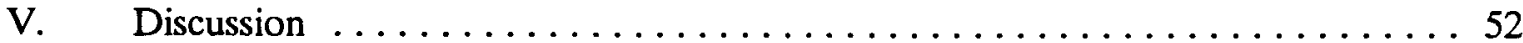

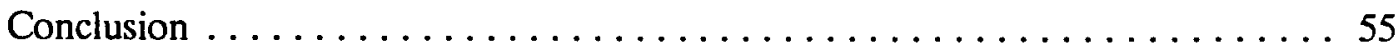

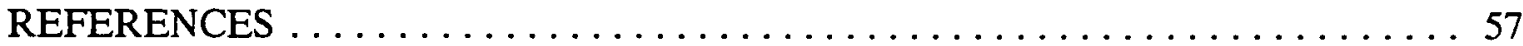

APPENDIX - Passive Alcohol Sensor Training Materials $\ldots \ldots \ldots \ldots \ldots \ldots \ldots$ A-1

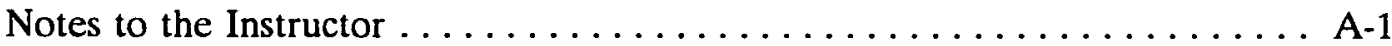

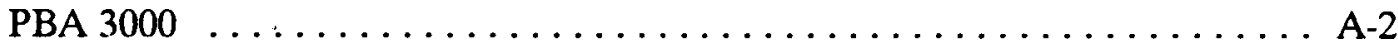

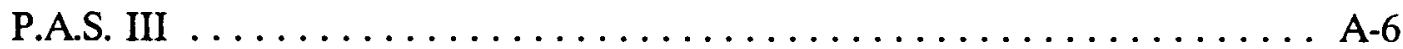

Mark X ....................... A 


\section{List of Tables}

Table Number $\quad \underline{\text { Page }}$

1. Fatally Injured Drivers by Age, $1985-1989 \ldots \ldots \ldots \ldots \ldots \ldots \ldots \ldots \ldots$

2. Summary of Reduced BAC Drinking and Driving Laws for Underage Drivers 2

3. Laboratory Tests of Passive Alcohol Sensors . . . . . . . . . . . 8

4. Effect of Passive Alcohol Sensors on Initial Screening at Sobriety

Checkpoints ........................ 10

5. Ability of Passive Sensors to Discriminate Above/Below BAC Thresholds . . 11

6. Screening Effectiveness of Passive Sensors at Sobriety Checkpoints . . . . . 12

7. Use of Passive Alcohol Sensors on Normal Patrols: Accuracy and Arrests .. 13

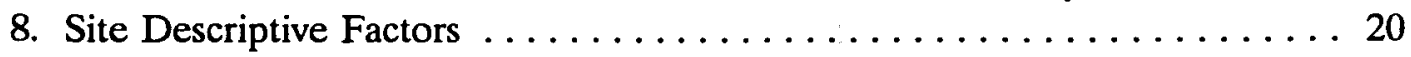

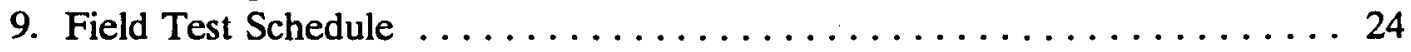

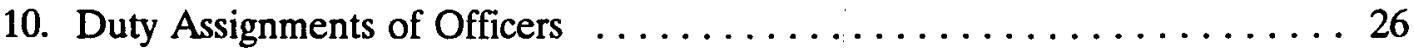

11. Passive Alcohol Sensor Estimated Application Summary . . . . . . . . 28

12. Subjects on Whom Passive Alcohol Sensors Were Used . . . . . . . . . . . . 29

13. How Passive Alcohol Sensors Were Used - All Logged Uses . . . . . . . . 30

14. Time and Day of Sensor Usage (Excluding Checkpoint Data) . . . . . . 33

15. Day and Time Periods and Passive Alcohol Sensor Use . . . . . . . . . 34

16. Percent of Contacts Resulting in Alcohol-Related Arrests . . . . . . . . 35

17. Likelihood of Alcohol-Related Arrest ................. 36

18. DWI Arrests from Court Records, by Site and 6-Month Period . . . . . . . 37

19. Adjudication Results for Underage DWI Arrests, $1 / 91$ - 6/94, by Site . . . . 38

20. Adjudication Results for Underage DWI Arrests, by 6-Month Period . . . . . 39

21. Average BAC Values for Underage DWI Arrests, by Site and

6-Month Period ........................ . 40

22. Adjudication Results for Underage DWI Arrests, by BAC Category . . . . . 40

23. Underage Liquor Law Violations, by Site and 6-Month Period . . . . . . . . 42 


\section{List of Figures}

Figure Number $\quad$ Page

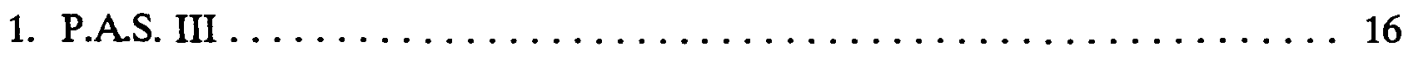

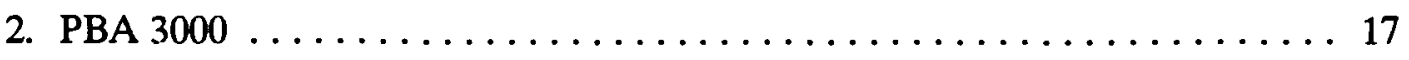

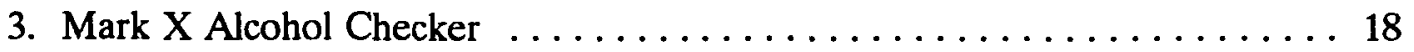

4. Passive Alcohol Sensor Estimated Applications . . . . . . . . . . . 28

5. Passive Sensor Use, by Officer Duty Assignment . . . . . . . . . . 31

6. Context of Passive Sensor Use ..................... 31

7. Percent of Contacts Leading to Alcohol-related Arrests . . . . . . . . . . 32

8. Underage DWI Arrests, Site by Time Period . . . . . . . . . . . . 38

9. Underage Liquor Law Arrests . . . . . . . . . . . . . . . . 43 


\section{INTRODUCTION}

The overall rate of alcohol-involved fatalities is high for young drivers. Data from the Fatal Accident Reporting System (FARS) which show the numbers of fatalities per 10,000 licensed drivers are shown in Table 1 (for the contiguous 48 states, 1985 - 1989; Preusser, Ulmer, and Preusser, 1992). For BACs above .00\%, drivers 16 and 17 years of age have about twice the rate of fatalities as drivers ages 25 and older; drivers ages $18-20$ and $21-24$ have rates of fatalities about three times as high as drivers ages 25 and older.

Values in Table 1 drop off more sharply from lower to higher BACs for young drivers. That is, young drivers have relatively more of their fatal injuries at low BACs. Drivers 16 and 17 have 16 percent of their alcohol-involved fatalities at BACs from .01\% through $.049 \%$, another 23 percent at BACs of $.05 \%$ through $.099 \%$. For drivers $18-20$, comparable values are 10 percent and 17 percent, respectively. For drivers $21-24$, they are 5 percent and 12 percent; for drivers 25 and older, they are 8 percent and 9 percent.

Table 1. Fatally Injured Drivers by Age, 1985 - 1989

\begin{tabular}{|c|c|c|c|c|c|}
\hline & \multicolumn{4}{|c|}{ Age Group } & \multirow{2}{*}{ Total } \\
\hline & $16 \cdot 17$ & $18-20$ & $21-24$ & $25+$ & \\
\hline $\begin{array}{l}\text { Drivers Killed (Annual } \\
\text { Average) }\end{array}$ & 1216 & 2901 & 3697 & 16,804 & 24,618 \\
\hline $\begin{array}{l}\text { Rate per } 10,000 \text { Licensed } \\
\text { Drivers }\end{array}$ & 3.47 & 3.44 & 2.85 & 1.31 & 1.61 \\
\hline Pct. Tested for BAC & $70.0 \%$ & $74.4 \%$ & $75.9 \%$ & $71.5 \%$ & $72.4 \%$ \\
\hline $\begin{array}{l}\text { Pct. } \mathrm{BAC}>=.01 \% \\
\text { Pct. } \mathrm{BAC}>=.05 \% \\
\text { Pct. } \mathrm{BAC}>=.10 \%\end{array}$ & $\begin{array}{l}35.7 \% \\
30.0 \% \\
21.9 \%\end{array}$ & $\begin{array}{l}53.5 \% \\
48.0 \% \\
39.1 \%\end{array}$ & $\begin{array}{l}65.1 \% \\
61.9 \% \\
53.9 \%\end{array}$ & $\begin{array}{l}50.6 \% \\
46.8 \% \\
42.2 \%\end{array}$ & $\begin{array}{l}52.7 \% \\
48.5 \% \\
42.7 \%\end{array}$ \\
\hline $\begin{array}{l}\text { Alcohol-Related per } \\
\begin{array}{c}\text { 10,000 Licensed Drivers: } \\
\text { BAC }>=.01 \% \\
\text { BAC }>=.05 \% \\
\text { BAC }>=.10 \%\end{array}\end{array}$ & $\begin{array}{l}1.24 \\
1.04 \\
0.76\end{array}$ & $\begin{array}{l}1.84 \\
1.65 \\
1.35\end{array}$ & $\begin{array}{l}1.86 \\
1.77 \\
1.54\end{array}$ & $\begin{array}{l}0.66 \\
0.61 \\
0.55\end{array}$ & $\begin{array}{l}0.88 \\
0.78 \\
0.69\end{array}$ \\
\hline
\end{tabular}

In response to this problem, 25 states had established lower $\mathrm{BAC}$ limits for underage drivers by the summer of 1994 . Eleven of these states make any alcohol (or as much as might be 
in a single drink) illegal for all drivers younger than 21 years, the national minimum drinking age (MDA).

Note that these "zero tolerance" ${ }^{1}$ laws are not simply DWI laws with different BAC limits for youth. Penalties for violating zero tolerance laws are generally less severe than penalties for DWI convictions. Also, the zero tolerance limits in some states are coded as license restrictions, comparable to the requirement to wear corrective lenses.

Table 2. Summary of Reduced BAC Drinking and Driving Laws for Underage Drivers (from IIHS, December 93, and MADD, Summer 1994)

\begin{tabular}{|c|c|c|c|c|}
\hline BAC Limits & $<18$ & $\begin{array}{l}\text { Ages } \\
<19\end{array}$ & $<21$ & Total \\
\hline $0.00 \%$ & 1 & 1 & 7 & 9 \\
\hline $0.01 \%$ & 0 & 0 & 1 & 1 \\
\hline $0.02 \%$ & 1 & 0 & 9 & 10 \\
\hline $0.04 \%$ & 1 & 0 & 1 & 2 \\
\hline $0.05 \%$ & 2 & 0 & 0 & 2 \\
\hline $0.07 \%$ & 0 & 0 & 1 & 1 \\
\hline Total & 5 & 1 & 19 & 25 \\
\hline
\end{tabular}

Enforcing DWI laws is difficult. Preusser et al. (1992) used FARS results together with Federal Bureau of Investigation's Uniform Crime Report (UCR) statistics on DWI arrests to show that, for each fatally injured driver, only about one-third as many drivers ages 16 and 17 are arrested for DWI as are drivers ages 25 and more. Only about two-thirds as many drivers ages 18 - 20 are arrested for DWI as are drivers ages 25 and above.

Preusser et al. cited four kinds of obstacles to making DWI arrests of underage drivers. First, drinking and driving patterns for youth do not match in time or location the enforcement patterns developed for adult drinking drivers. Youth drink at private parties or homes and are not as likely to be driving on the main roads around bars and restaurants where much of DWI enforcement is focussed. Next, young drivers at low but dangerous BACs may not exhibit the same kinds of cues in their driving behavior that officers use to identify impaired drivers.

1 The term "zero tolerance" will be used for simplicity in this paper to refer to any of the reduced BAC laws for youth described in Table 2, although some of the laws are more accurately characterized as "reduced tolerance" laws. 
Preusser et al., for example, suggest a level of cognitive impairment that doesn't reveal performance problems in normal driving but may increase risk-taking and reduce the ability to recognize and respond to hazards. Finally, prosecution of underage drinking drivers, particularly at relatively low BACs, often does not receive much emphasis. This would, in turn, reduce the incentive for officers to make such arrests.

For these same reasons and more, it is likely that enforcing zero tolerance laws is even more difficult. There are likely to be fewer or different behavioral cues to provide probable cause for the initial stop. Also, once an officer has stopped a young driver, it is more difficult to detect the smaller amounts of alcohol which constitute a zero-tolerance violation. For example, youth just above a limit of, say, .02\%, may not exhibit the traditional cues such as slurred speech, and the officer may miss a faint smell of alcohol. In addition, the officers' traditional training, focus, and experience has traditionally targeted drivers who are over the adult limit of $.10 \%$ or drivers who show obvious signs of impairment. Most officers simply have less experience and fewer guidelines for detecting zero tolerance violations.

In the past 10 years or so, passive alcohol sensor technology has been developed to assist in this initial determination. The sensors are designed to sample the air immediately around the suspect for signs of exhaled alcohol - the same air that is available to the officer's nose.

Studies have been done testing passive sensors in the laboratory, at sobriety checkpoints. and in controlled patrol operations. In general, the sensors have been able to discriminate between the presence and absence of alcohol and have been able to provide information on the approximate $\mathrm{BAC}$ levels. Using passive sensors, officers have made better decisions, detaining and arresting fewer drivers below the target $B A C$ threshold and more drivers at or above the target BAC. These studies have emphasized arrests at adult BAC threshold levels, variously .05\% to $.10 \%$.

The current study represents the next step in research involving passive sensors. It uses three different kinds of passive sensors with police officers in a wide variety of duty conditions. Participating in the study were three municipal police departments in three zero tolerance states. The study addresses three questions.

1. In patrol activities ranging from youth patrol to DWI patrol to sobriety checkpoints, how effective are the passive alcohol sensors? In this study, officers were asked to integrate passive sensors into their normal work flow. To an extent unmatched in previous research, the officers were in control of exactly how and when they used the devices. Thus this test involved basic acceptance of the devices on their own merits as well as, once used, how effective they were.

2. Is use of the passive alcohol sensors associated with increases in alcohol-related arrest rates? If so, do the increases relate directly to the ways the devices were used, or might they be due to a general heightened emphasis on alcohol and driving offenses associated with participation in this study? Are prosecutions more or less difficult in cases in which the passive sensors were employed? 
3. Based on their experiences, what do the officers feel are important capabilities and characteristics for passive alcohol sensors that they would use regularly? In part, this involves evaluating the three specific sensors used in the study and identifying their strengths and weaknesses for the kinds of situations in which they were used. More broadly, the study sought to identify critical features of the usage situations (such as officer safety and control) and recommend characteristics for passive alcohol sensors which would be most effective and accepted.

The remainder of this report is organized into four sections:

II. Background - a detailed review of the research with passive alcohol sensors. The review describes the devices that are generally available, the research supporting their effectiveness, and the context in which they have been used and tested.

III. Method - a description of the three sensors used in the study, the three municipal departments, and the kinds of uses for the sensors in the departments. The section describes the parameters of the tests (when, how long, how many, how used) and the kinds of data and analyses performed to document the tests and their results. The section also describes other data collected to document the department's alcohol-related arrest and adjudication experience in the years preceding the test and during the test period.

IV. Results - a detailed description of results as they relate to the three objectives described above.

V. Discussion.

\section{Terminology}

Throughout this report, a number of terms and acronyms are used frequently. For convenience and clarity, they are described here:

Adult - Anyone at or above the minimum drinking age (MDA) (i.e., 21 or older).

BAC - Blood alcohol concentration.

DWI - Driving While Intoxicated. This may be a "per se" offense (e.g., driving with a BAC at or above a limit such as $.10 \%$ is a violation) or one based on evidence including behavioral indications of impairment. For consistency, this term is used throughout this paper even though individual jurisdictions may use other terms (such as DUI) for these offenses.

Evidentiary Breath Test - Breath test taken using approved procedures on a device which is certified and calibrated to provide $\mathrm{BAC}$ values that can be used in court.

MDA - Minimum drinking age; 21 years in all states. 
Passive Alcohol Sensor - Device that samples ambient air in order to detect the presence of alcohol. (Although the acronym PAS is often used as a generic term, it is not used in this report because of possible confusion with specific device names.) Passive sensors are intended to sample air exhaled by a subject (driver) by means of procedures which ensure that the passive sensor's reading is an approximate indication of the subject's BAC. Most, but not all, devices marketed as passive alcohol sensors use alcohol-specific fuel cells, use fans or pumps to draw in a measured air sample, and register estimated BACs by means of a digital display or an array of light bars. The following passive sensors are discussed in this report (ones actually tested were the P.A.S. III, the PBA 3000, and the Mark X):

- Passive sensors integrated into police flashlights all come from a single development path; all use alcohol-specific fuel cells and air pumps. The first device was the Lion PAS which provided a digital readout; the next generation was the NPAS P.A.S., which used a 10-bar light array divided into three green, four yellow, and three red bars. Next were the P.A.S. II and then the P.A.S. III units, similar but improved; they are now produced by Public Service Technologies, Inc.

- Life Loc, Inc., Passive Breath Analyzers. The PBA 2000 and PBA 3000 units use alcohol-specific fuel cells and air pumps. They have ultrasonic distance-measuring equipment which ensures breath samples are taken at appropriate distances from the subjects and also adjusts readings for different distances within the acceptable range. They have internal "computers" which record the time, date, mode, and BAC for each use of the device; these records can later be printed or transferred to a personal computer. The PBA 3000 can also be used in a direct measurement mode in which the subject exhales into a mouthpiece. In this mode and with an attached printer, it is a U.S. DOT-approved non-evidentiary Portable Breath Test (PBT) device.

- Guth Laboratories, Inc., Mark X Alcohol Checker. This is a small device which uses a tin oxide ceramic sensor to detect alcohol. It does not have an air pump, but instead is intended to be waved gently in front of the subject when used as a passive alcohol sensor. The Mark X can also be used in a direct measurement mode in which the subject exhales through a mouthpiece. The Mark X indicates readings by six orange and red light bars; a reading in the red region (nominally, $.08 \%$ or higher) also generates an audible beep.

- CMI/MPH AlcolmeterTM Voice Activated Sensor (VAS). This device is shaped somewhat like a hand-held microphone. It uses an alcohol-specific fuel cell and an air pump, and it indicates BACs of 0 or $.02 \%-.11 \%$ or higher by means of a light bar array.

- Honda Motor Corp.-sponsored passive sensor. This was the first passive alcohol sensor developed for police field use. Although seeing some field use in Japan, in this country it was used only in tests and may best be thought of as a prototype. It used a sensor which responded to a number of chemicals in addition to alcohol, it needed to achieve an internal temperature of $450^{\circ} \mathrm{F}$, and it needed calibration 
(sensitivity adjustment) before each use. The Honda sensor indicated either no alcohol (green light) or some alcohol (red light).

PBT - Preliminary Breath Tester. These devices are certified by the U.S. Department of Transportation for accuracy. They are intended to be used in the field, usually by means of the subject blowing through a mouthpiece, to provide an accurate estimate of the subject's BAC. They are not necessarily as accurate as an evidentiary breath tester, and the field conditions under which they are used are less controlled than the conditions for evidentiary tests. PBT readings may be admissible in court. PBTs mentioned in this report include the Lion Labs Alcolmeter S-D2 and Intoximeter Alco-Sensor 2 and 3. Used in direct mode with its attached printer, the PBA 3000 is also classed as a PBT.

Youth - Anyone below the MDA.

Zero Tolerance - Reduced-BAC law for youth drivers. 


\section{BACKGROUND}

Beginning in the early 1980 s, passive alcohol sensors were developed to provide a convenient and non-intrusive way of estimating someone's BAC. Devices have evolved over the last decade, from early prototype models to the current "third" generation of production models. Ones designed for police use may have additional features such as allowing for PBT-like direct measurement of BAC (with a mouthpiece for blowing directly into the sensor) or being incorporated into a police flashlight. This section describes the available types of devices in more detail and summarizes the research that has been done to test and demonstrate their effectiveness.

\section{Laboratory Tests of Passive Alcohol Sensors}

Laboratory studies have played an important role in demonstrating that passive alcohol sensors can detect and measure breath alcohol levels. Voas (1983) tested a very early passive alcohol sensor, one developed in Japan by Nippon Seiki Company for Honda Motors. The device, which used a red or green light to indicate presence or absence of alcohol, was not very practical. Its sensor had to operate at an internal temperature of $450^{\circ} \mathrm{F}$, it needed calibration before each use, and it was sensitive to a number of substances in addition to alcohol. In over 1,880 laboratory trials. with human subjects, however, it did reliably detect the presence of alcohol. The results for tests done at a distance of $6^{\prime \prime}$ and an air temperature of $70^{\circ} \mathrm{F}$, the most sensitive condition, are summarized in the first part of Table 3. The same study included a field test component which is described later in this section.

Farina (1988) tested two "first generation" devices ${ }^{2}$, the Lion Alcolmeter PAS and a modified version of it, the National Patent Analytical Systems, Inc., (NPAS) P.A.S. device. (These have since evolved into the Public Service Technologies, Inc., P.A.S. II and P.A.S. III passive alcohol sensors. All four devices are based on alcohol-sensitive fuel cells and are combined with a police-type flashlight. All have pumps to draw a measured amount of air into the fuel cell.) The Lion PAS provided a three-digit readout which could be converted to BAC values (e.g., a scale value of "030" corresponded to a BAC of .05\%). The NPAS P.A.S. used 10 light bars ( 3 green bars, nominally $0-.05 \% ; 4$ yellow bars, nominally $.05 \%-.16 \%$; and 3 red bars, nominally $.16 \%$ and above). In this test, Farina used simulators to generate air corresponding to BAC levels of $.00 \%, .02 \%, .05 \%, .08 \%, .10 \%, .12 \%$, and $.15 \%$. His criterion for the Lion PAS was whether the device accurately indicated that the test air was at or above $.05 \%$ or below $.05 \%$. Although not stated in that form in his report, Farina's results for the NPAS can be expressed in terms of the percent meeting or exceeding the threshold value of 3 green plus at least 1 yellow bar as a function of true BAC level. These results are also shown in Table 3.

2 Although a number of the Honda devices were sold to Japanese police departments, the unit may best be viewed as a prototype model or feasibility demonstration. 
In a laboratory test with human subjects, Lestina and Lund (1989) tested the NPAS P.A.S. along with the Life Loc., Inc., Passive Breath Analyzer (PBA) 2000. The PBA 2000 used an alcohol-sensitive fuel cell and an air pump to draw in sample air. It included a sound-wave-based facility for measuring the distance from the unit to the subject and adjusting the reading accordingly. Readouts could be either in 3-digit BAC values or Pass/Warning/Fail values. The PBA 2000 includes internal memory for retaining date, time, and BAC reading; these data can be printed directly or downloaded to a personal computer.

Lestina and Lund compared readings with the NPAS and Life Loc units with readings from a Lion S-D2 Alcolmeter and estimated, for standard actual BAC levels, the percent of positive (".10\% or higher") readings from each passive unit. The results are shown in Table 3 for the best testing conditions (all tests were done at room temperature; the best distance was $5^{\prime \prime}$; the best threshold criterion for the NPAS unit was one yellow bar lit; the best threshold criterion for the Life Loc unit was a reading of $.04 \%$ ).

Overall, all units demonstrated sensitivity to alcohol. While none was perfect, each particularly the production NPAS and Life Loc devices - provided usually reliable information about whether the subject was at or above a threshold value of $.05 \%$ or $.10 \% \mathrm{BAC}$.

Table 3. Laboratory Tests of Passive Alcohol Sensors

\begin{tabular}{||c|c|c|c|c|c||}
\hline \multirow{2}{*}{ Source } & Device & Criterion & \multicolumn{3}{|c|}{$\begin{array}{c}\text { True BAC / } \\
\% \text { Meeting Criterion }\end{array}$} \\
\hline \hline Voas, 1983 & Honda & $\begin{array}{l}\text { \% cases detected } \\
\text { (any) alcohol }\end{array}$ & $.02-.04 \%$ & $.05-.09 \%$ & $>=.10 \%$ \\
\cline { 4 - 6 } & & & $64 \%$ & $77 \%$ & $91 \%$ \\
\hline
\end{tabular}

\begin{tabular}{||l|l|l|c|c||}
\hline \multirow{3}{*}{ Farina, 1988} & Target: $>=.05 \%$ & $.00, .02 \%$ & $.05, .08, .10, .12, .15 \%$ \\
\cline { 2 - 5 } & Lion PAS & $\%$ reading $>=030$ & $0 \% *$ & $77 \%$ \\
\cline { 2 - 5 } & NPAS P.A.S. & $\begin{array}{l}\text { \% reading }>=1 \\
\text { yellow bar }\end{array}$ & $18 \% *$ & $100 \%$ \\
\hline
\end{tabular}

\begin{tabular}{||l|l|l|c|c|c|c||}
\hline \multirow{2}{*}{$\begin{array}{l}\text { Lestina and } \\
\text { Lund, } 1989\end{array}$} & NPAS P.A.S. & $\begin{array}{l}\text { Target: }>=.10 \% \\
\text { yellow bar }\end{array}$ & $.02 \%$ & $.05 \%$ & $.10 \%$ & $.15 \%$ \\
\cline { 2 - 7 } & $\begin{array}{l}\text { Life Loc PBA } \\
\mathbf{2 0 0 0}\end{array}$ & $\begin{array}{l}\text { \% reading .04\% or } \\
\text { higher }\end{array}$ & $12 \% *$ & $34 \% *$ & $80 \%$ & $99 \%$ \\
\hline
\end{tabular}

* False positives; other values are "true positives." 


\section{Field Tests of Passive Alcohol Sensors}

The first field study using a passive alcohol sensor was conducted by Voas (1983), who used the Honda sensor on normal DWI patrol. The device, together with a researcher who calibrated it and recorded data, was used by two District of Columbia police officers on weekend nights. Data were collected in December and January, when the temperature approached but did not drop below freezing. A total of 86 drivers were tested with the Honda sensor and subsequently with an Alco-Sensor 2 or 3 (both U.S. DOT-approved PBTs). In general, the higher the true BAC (as measured by the Alco-Sensor), the more likely the Honda sensor was to indicate the presence of alcohol. For true BACs of $.00-.01 \%$, the sensor identified 6 percent as having had alcohol; for true BACs of $.02-.04 \%, 21$ percent tested positive on the Honda; for true BACs of $.05-.09 \%, 53$ percent tested positive; and for true BACs of $.10 \%$ or more, 85 percent tested positive.

Several studies have used sobriety checkpoints to assess the ability of passive alcohol sensors to improve detection and detention of drivers who had been drinking. In such studies, passive sensors were used by officers in an initial brief car-side interview. Officers used that interview to identify possible DWI drivers (who were then detained, given behavioral tests and preliminary breath tests, and - if conditions warranted - arrested). The officers were given guidelines as to what reading on the passive sensor would likely correspond to impairment, but they were free to detain or release drivers based on their total impressions.

At checkpoints in Charlottesville, Virginia, Jones and Lund (1986) tested the effectiveness of the Lion PAS device. The tests were conducted as part of a broader test of well-publicized sobriety checkpoints (see Voas, Rhodenizer, and Lynn, 1984). They were done in October and November, 1984, when temperatures were likely to have been moderate to cool. During initial screening interviews, officers sought to identify drivers with BACs of $.05 \%$ or higher. (Targeted drivers were detained and given behavioral tests and a preliminary breath test. Those between $.05 \%$ and $.099 \%$ were given warnings; those at $.10 \%$ or higher were arrested for DWI. Drivers not detained were given preliminary breath tests by researchers.) In about half the checkpoint sessions, passive sensors were used to aid officers in their initial screening ( $\mathrm{n}=778$ drivers); in the remaining sessions, officers performed their initial screening with no passive sensor $(n=866$ drivers). As shown in Table 4, when using passive sensors the officers detained significantly more of the drivers whose BACs were at or above the $.05 \%$ threshold and detained significantly fewer of the drivers whose BACs were below the threshold.

In a similar study, Ferguson, Wells, and Lund (1993) tested the Public Service Technologies P.A.S. II passive alcohol sensor at checkpoints. In the initial screening interview, officers sought to identify and detain drivers with BACs of at least $.05 \%$. Detained drivers were given behavioral tests and preliminary breath tests, and those with BACs above $.10 \%$ were arrested for DWI. Half the time, officers used the P.A.S. II in the initial screening interviews (n $=2,506$ drivers); half the time, they used no such device ( $n=2,443$ drivers). When the P.A.S. II was used, fewer drivers below $.05 \%$ were detained; more drivers at $.05 \%$ or higher were detained. The results are summarized in Table 4. 
Table 4. Effect of Passive Alcohol Sensors on Initial Screening at Sobriety Checkpoints

\begin{tabular}{|c|l|l|l|l|c|c||}
\hline \multirow{2}{*}{ Source } & \multicolumn{1}{|c|}{ Device } & \multicolumn{2}{|c|}{ Criterion } & \multicolumn{3}{|c|}{$\begin{array}{l}\text { True BAC / } \\
\% \text { Detained }\end{array}$} \\
\hline \hline \multirow{3}{*}{$\begin{array}{l}\text { Jones and } \\
\text { Lund, 1986 }\end{array}$} & & $\begin{array}{l}\text { Goal: Identify } \\
\text { drivers to detain } \\
\text { for further testing }\end{array}$ & $\begin{array}{c}< \\
.02 \%\end{array}$ & $\begin{array}{c}.02- \\
.04 \%\end{array}$ & $\begin{array}{c}.05- \\
.099 \%\end{array}$ & $\begin{array}{c}>= \\
.10 \%\end{array}$ \\
\cline { 2 - 8 } & Lion PAS & 030 or higher $* *$ & $1 \% *$ & $8 \% *$ & $45 \%$ & $68 \%$ \\
\cline { 2 - 8 } & none & n.a. & $2 \% *$ & $18 \% *$ & $24 \%$ & $45 \%$ \\
\hline
\end{tabular}

\begin{tabular}{|l|l|l|l|l|l|l||}
\hline \hline $\begin{array}{l}\text { Ferguson, } \\
\text { Wells, and } \\
\text { Lund, } 1993\end{array}$ & P.A.S. II & 4 bars or more $* *$ & $1 \% *$ & $18 \% *$ & $39 \%$ & $71 \%$ \\
\cline { 2 - 6 } & none & n.a. & $1 \% *$ & $23 \% *$ & $26 \%$ & $55 \%$ \\
\hline
\end{tabular}

* False positives; other values are "true positives."

** Guidelines for officers to consider in their decisions to detain.

Foss, Voas, and Beirness (1993) conducted interviews with Minnesota drivers between 10 $\mathrm{pm}$ and 3 am during September, 1990. Although the methods were roadside survey rather than sobriety checkpoint, about 94 percent of all drivers approached provided breath samples, yielding sampling nearly identical with what would be found in police-operated checkpoints. The passive sensor used was the CMI/MPH Alcolmeter Voice Activated Sensor (VAS), which looks like a hand-held microphone. Once turned on, it automatically samples the air when the subject speaks or blows softly on the device. It uses an alcohol-specific fuel cell, and it displays readings by means of a 10-bar segment corresponding to readings of $.02 \%$ to $.11 \%+$ BAC. In this study, subjects were asked to blow toward the device. Comparison readings were provided by Intoximeter Alco-Sensor 3 hand-held PBTs.

A total of 1,145 subjects provided readings on both instruments. Results from the VAS units were scored according to their ability to distinguish BAC levels above and below four criteria: $.02 \%$, the level for youth in several states; .05\%, the current limit in most European countries and for youth in two states; $.08 \%$, the current limit for drivers $>=21$ years old in several states; and $.10 \%$, the current $21+$ limit in the remaining states. The "best" criterion value for the VAS units and the results for all 1,145 subjects are provided in Table 5. A larger study conducted by Meyers, Perrine, and Foss (1994) on more than 22,000 drivers in the Columbus, Ohio, area reported comparable findings. It should be noted that, although the VAS is designed to measure during normal speech, the actual testing procedures used in these studies was not truly passive. That is, testers required specific action on the part of the subject, i.e., blowing gently toward the device. 
Table 5. Ability of Passive Sensors to Discriminate Above/Below BAC Thresholds

\begin{tabular}{|c|c|c|c|c|}
\hline Source & Device & Criterion & \multicolumn{2}{|c|}{$\begin{array}{c}\text { True BAC / } \\
\% \text { Meeting Criterion }\end{array}$} \\
\hline \multirow{7}{*}{$\begin{array}{l}\text { Foss, Voas, } \\
\text { and Beirness, } \\
1993\end{array}$} & & $\begin{array}{l}\text { Goal: Identify } \\
\text { drivers }>=.02 \%\end{array}$ & $<.02 \%$ & $>=.02 \%$ \\
\hline & CMI/MPH VAS & $>=$ one bar lit & $3 \% *$ & $93 \%$ \\
\hline & & $\begin{array}{l}\text { Goal: Identify } \\
\text { drivers }>=.05 \%\end{array}$ & $<.05 \%$ & $>=.05 \%$ \\
\hline & CMI/MPH VAS & $>=$ four bars lit & $1.4 \% *$ & $83 \%$ \\
\hline & & $\begin{array}{l}\text { Goal: Identify } \\
\text { drivers }>=.08 \%\end{array}$ & $<.08 \%$ & $>=.08 \%$ \\
\hline & CMI/MPH VAS & $>=$ four bars lit & $3 \% *$ & $91 \%$ \\
\hline & & $\begin{array}{l}\text { Goal: Identify } \\
\text { drivers }>=.10 \%\end{array}$ & $<.10 \%$ & $>=.10 \%$ \\
\hline 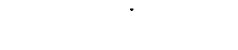 & CMI/MPH VAS & $>=$ five bars lit & $3 \% *$ & $82 \%$ \\
\hline
\end{tabular}

* False positives; other values are "true positives."

Preusser (1994) reported on the use of passive alcohol sensors as part of an integrated enforcement program designed to reduce alcohol-impaired driving and increase seat belt use. (For a description of the entire study, see Wells, Preusser, and Williams, 1992.) The NPAS P.A.S. sensor was used at checkpoints and during regular and DWI patrols. Across 54 checkpoints, 5,295 drivers were screened with the P.A.S. unit and subsequently tested for actual BAC levels. Table 6 shows, for two possible screening thresholds, the percentage of positive (threshold or higher) readings on the P.A.S. device for four levels of true BAC values. 
Table 6. Screening Effectiveness of Passive Sensors at Sobriety Checkpoints

\begin{tabular}{|c|c|l|c|c|c|c||}
\hline \multirow{2}{*}{ Source } & Device & \multicolumn{1}{|c|}{ Criterion } & \multicolumn{4}{|c|}{$\begin{array}{c}\text { True BAC / } \\
\text { \%eeting Criterion }\end{array}$} \\
\hline \hline \multirow{3}{*}{ Preusser, 1994 } & & $\begin{array}{l}\text { \% of cases } \\
\text { exceeding P.A.S. } \\
\text { criterion }\end{array}$ & $\begin{array}{c}< \\
.01 \%\end{array}$ & $\begin{array}{c}.01- \\
.049 \%\end{array}$ & $\begin{array}{c}.05- \\
.099 \%\end{array}$ & $\begin{array}{c}>= \\
.10 \%\end{array}$ \\
\cline { 2 - 7 } & \multirow{2}{*}{ NPAS P.A.S. } & 3 bars or more & $8 \%^{*}$ & $35 \% *$ & $65 \%$ & $72 \%$ \\
\cline { 2 - 7 } & & 4 bars or more & $5 \% *$ & $24 \% *$ & $53 \%$ & $57 \%$ \\
\hline
\end{tabular}

* False positives; other values are "true positives."

Ferguson et al. (1993) and Preusser (1994) asked officers who had used the passive sensors for their reactions. In the former study, the majority of the officers ( 67 percent) reported that the passive sensors improved their ability to detect alcohol-impaired drivers. The remaining officers, as a group, made relatively few arrests at the checkpoints and identified far fewer of the drivers with BACs $>=.05 \%$ ( 30 percent, compared to 68 percent for the officers who found the passive sensors to be valuable). Ferguson et al. suggested that the officers who did not rate the passive sensors positively were ones who were not able to use them effectively.

The officers asked by Preusser (1994) had used the passive sensors at checkpoints, on regular patrol, and on DWI patrol. Of the officers who had used the passive sensors at checkpoints, 95 percent felt they were valuable and should be used there. For other applications, reviews were less positive. Preusser found that the use of the passive sensors on regular patrol declined across the two years of the study. Usage stayed high for the DWI officers, although they seemed to feel the units were of only mixed value. Comments suggested that the problems were not with the concept of passive sensors but with the actual devices. The most significant problems with the units were specific to those units - poor battery life and mechanical reliability. Other concerns were with what officers felt were design weaknesses and with the fact that the passive mode of operation made the units susceptible to alcohol from a number of sources other than just drivers who had been drinking (e.g., drinking passengers, alcohol-based hair spray, or alcoholbased after-shave lotions).

In a broad test of the effectiveness of passive sensors in patrol operations, Kiger, Lestina, and Lund (1991) put Life Loc PBA 3000 units in the hands of 16 police officers in Columbus, Ohio. Half were freeway patrol officers, half were assigned routine precinct patrol duty. They used the units on alternate nights, used no passive alcohol sensors the other nights. Units were used during the initial contact on all traffic stops, and officers followed up with field sobriety tests and arrests as they felt appropriate. Drivers who were released were given preliminary breath tests in the field by observers using Lion S-D2 Alcolmeters; arrested drivers provided BAC values at the facility to which they were taken. 
The PBA 3000 units were set to display Pass (for BACs <.03\%), Warning (for BACs from $.03 \%$ to $.099 \%$ ), or Fail (for BACs $>=.10 \%$ ). Officers were instructed that Warning or Fail meant that it was likely that the driver had consumed significant amounts of alcohol. They used the passive sensor readings as aids or guidelines for followup investigation. Their goal was to arrest drivers with BACs of $.10 \%$ or more or drivers with BACs between .05 and $.099 \%$ who appeared impaired through behavioral tests.

Two measures of sensor effectiveness were used. First, PBA 3000 readings were compared with the Lion S-D2 Alcolmeter readings (or the evidentiary test readings for the drivers who were arrested). These results, shown in the first part of Table 7, indicated that the PBA 3000 provided few Warning or Fail readings for drivers whose BAC was below .05\% and provided many Warning or Fail readings for drivers whose BAC was above $.05 \%$ and above $.10 \%$. Second, the percentages of drivers within specific $B A C$ ranges who were arrested were compared with and without the passive sensor. In both conditions, virtually no drivers ( 1 percent) with true BACs below $.05 \%$ were arrested. For drivers with BACs at or above $.10 \%$, somewhat more were arrested when the passive sensor was used. Use of the passive sensor produced striking differences in outcomes with moderate BACs. Almost none of them ( 4 percent) were arrested when the passive sensor was not used; more than $1 / 3$ were successfully identified and arrested with the use of the passive sensor. These results are shown in the bottom part of Table 7 .

Table 7. Use of Passive Alcohol Sensors on Normal Patrols: Accuracy and Arrests

\begin{tabular}{|c|c|c|c|c|c|}
\hline Source & Device & Criterion & & $\begin{array}{l}\text { True BAC } \\
\text { eeting Cri }\end{array}$ & ion \\
\hline \multirow{6}{*}{$\begin{array}{l}\text { Kiger, } \\
\text { Lestina, and } \\
\text { Lund, } 1991\end{array}$} & & $\begin{array}{l}\text { Target: Identify } \\
\text { drivers }>=.05 \%\end{array}$ & $<.05 \%$ & $.05-.099 \%$ & $>=.10 \%$ \\
\hline & PBA 3000 & Warning or Fail & $3 \% *$ & $64 \%$ & $81 \%$ \\
\hline & & & \multicolumn{3}{|c|}{$\begin{array}{l}\text { True BAC / } \\
\% \text { Arrested }\end{array}$} \\
\hline & & $\begin{array}{l}\text { Arrest if }>=.10 \% \\
\text { or if }>=.05 \% \text { and } \\
\text { "impaired" }\end{array}$ & $<.05 \%$ & $.05-.099 \%$ & $>=.10 \%$ \\
\hline & PBA 3000 & Warning or Fail ${ }^{* *}$ & $1 \%$ & $37 \%$ & $77 \%$ \\
\hline & none & n.a. & $1 \%$ & $4 \%$ & $69 \%$ \\
\hline
\end{tabular}

* False positives; other values are "true positives."

** Guidelines for officers to consider in their decisions to detain. 


\section{Summary}

In all the studies reviewed, passive alcohol sensors were very effective in differentiating between drivers who had not been drinking and those who had been drinking. The devices were also accurate in identifying drivers at or above various criterion BAC levels. Use of the passive sensors led to fewer high-BAC drivers escaping arrest and fewer low-BAC or zero-BAC drivers being detained. These results set the stage for the current study, which extends testing into conditions more like those that would exist for police departments deploying passive sensors without the benefit of an on-site, facilitating research staff. 


\section{METHOD}

The study was centered around a field test of passive alcohol sensors - how they are accepted and used in normal police operations, how well they identify subjects who had been drinking and/or their blood alcohol levels, and whether their use impacted arrest and adjudication statistics. The study included four steps:

1. Identify passive sensor models for testing. Passive sensors were considered for inclusion in the study if they had been used in previous research or were being marketed for use by police as passive sensors. Four "current technology" devices were identified. At the time of the study, only three of these passive sensors were generally available for purchase and use. Those three were included in the study.

2. Select sites to participate in testing. Sites were sought in states with zero tolerance laws for youth. Mid-size municipal police departments were screened, and ones were selected which had active DWI enforcement and large numbers of under-21 drivers within their jurisdiction. Three departments were chosen, to facilitate a study design in which the three kinds of passive alcohol sensors were rotated among the departments so that, over three test periods, each department gained experience with all three devices. Departments in three different states were chosen to explore differences in state laws and practices and in climate.

3. In a balanced design, provide each of the three devices to each department for one test period. Each test period lasted about two months. For each test period, officers were trained in the use of that period's device, and then they carried and used the devices during their normal duties. At the end of the period, officers were debriefed in focus-group discussions. They were also asked to provide summary logs of their use of the devices and brief written evaluations of them.

4. Collect background information about the departments, including data on arrests which might be impacted by the use of passive alcohol sensors - DWI arrests and youth-oriented liquor law arrests.

\section{Identify Passive Sensor Models}

Initially, four devices had been identified for possible inclusion in this study. At the time details of the study design were being confirmed, one device - the CMI/MPH Alcolmeter ${ }^{\text {rm }}$ Voice Activated Sensor (VAS) - was not being marketed. Thus, the three remaining devices were utilized. 
Sniffer P.A.S.

The first device was the Sniffer P.A.S. from Public Service Technologies, Inc., of Fredericksburg, Virginia. For the very first weeks of the study, the Sniffer P.A.S. II model was used. For the second half of the first test period and for all of the second and third test periods, the Sniffer P.A.S. III model was used.

The P.A.S. III (and the very similar P.A.S. II) combine the "sniffer" with a large police flashlight (halogen light). The P.A.S. III uses an alcohol-specific fuel cell and microchip control. Both flashlight and passive alcohol sensor are controlled by a single pushbutton. When the button is depressed momentarily, the alcohol sensor is activated; an internal pump draws a measured air sample from a small side-entry port, and the amount of alcohol is reflected in a green-yellow-red 10-bar LED display. Another quick button press turns the alcohol sensor off. When the button is depressed and held for approximately onehalf second, the flashlight is turned on or off. The flashlight beam can be focussed for near (broad) or distant (narrow beam) use. While the flashlight is on, a thermostatically controlled heater is activated; the heater keeps the fuel cell at its optimal operating temperature.

The P.A.S. III has four small status lights located around the LED display. They indicate whether the battery is low and needs recharging; whether the fuel cell heater is on; whether the flashlight is on; and whether the air pump is actively drawing a sample. In addition, when the first green light on the LED display is illuminated it indicates that the passive sensor component is turned on. The LED display consists of three green, four yellow, and three red light bars. The first green bar indicates passive sensor on and $0.00 \%$ blood alcohol detected. Three green and one yellow bar correspond to approximately $0.03 \% \mathrm{BAC}$. Three green, four yellow, and one red bar correspond to about $0.08 \% \mathrm{BAC}$. All ten light bars are illuminated at a BAC of $0.12 \%$ or higher.

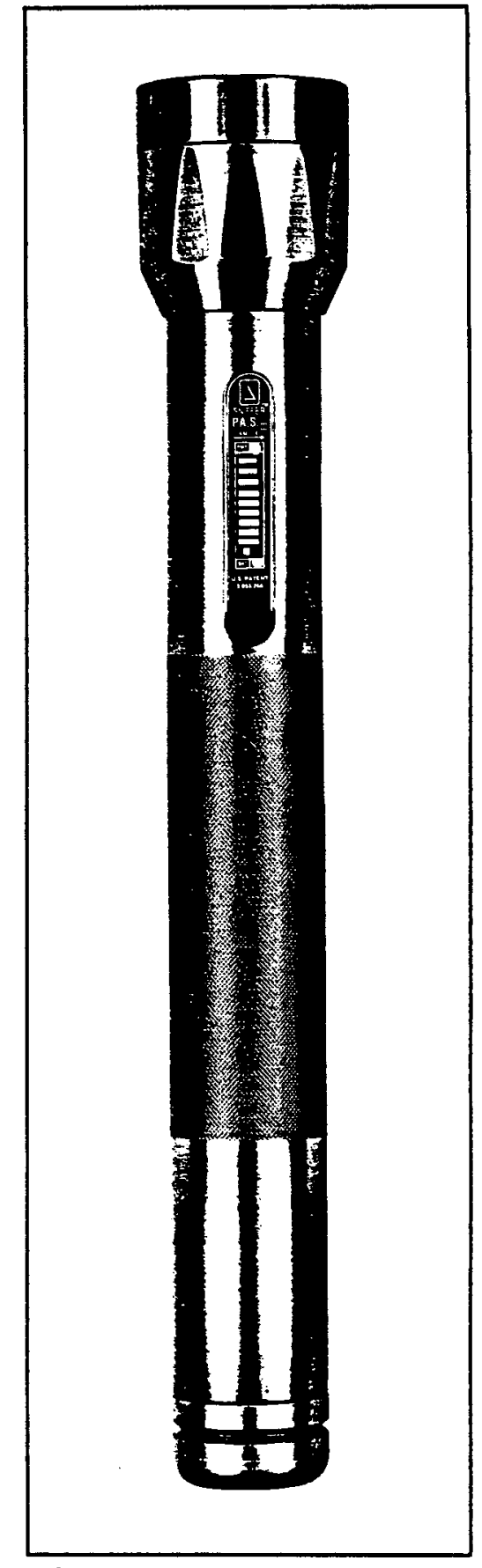

Figure 1. P.A.S. III

The P.A.S. III uses rechargeable batteries and has a "docking" charger which can be permanently mounted at the police station or an officer's home for off-duty hours recharging; it also has a cigarette-lighter adaptor for maintaining a charge within a police vehicle.

To use the P.A.S. III, officers are instructed to hold the "flashlight" (i.e., position the entry port) six to eight inches from the subject's mouth, wait until the subject begins speaking, and then activate the air pump. The pump draws a sample of air into a small port on the right side of the 
device, tests for alcohol, and discharges the sample from another port on the left side of the device.

\section{Life Loc PBA 3000}

The next device was the Life Loc PBA 3000 , which is available from Life Loc, Inc., of Wheat Ridge, Colorado. Like the P.A.S. III, the PBA 3000 uses an alcohol-sensitive fuel cell and an internal pump to draw in a measured air sample. In passive operation, the PBA 3000 is designed to be held about $5^{\prime \prime}$ to 8 " from the subject's mouth and activated when the subject is speaking toward the unit. The PBA 3000 contains a distance-measuring capability. When ready for use, the unit transmits ultrasonic pulses which measure whether the unit is at a proper distance to begin the test and also provide specific distance information which the internal computer uses to adjust its BAC calculations.

In addition to passive operation, the PBA 3000 can be used to accept a direct air sample blown through a mouthpiece. It is marketed as both a passive device and as a preliminary breath tester (PBT). In the direct mode, the PBA 3000 is a U.S. DOT-approved PBT device.

The PBA 3000 has a flush-mount keypad with four keys and, on the back of the unit, a recessed on-off switch. The operator presses single keys to select between direct and passive modes and again to start the pump to collect the air sample. Other key combinations control other functions and options of its internal computer.

Its display is an eight-character LCD panel; the display shows status, error, and programming information as well as BAC readings. The unit can be set to provide 3-digit $\mathrm{BAC}$ readings, 2-digit readings, Pass-Warning-Fail readings, or combinations of Pass-Warning-Fail for passive tests and digital readings for direct PBT tests.

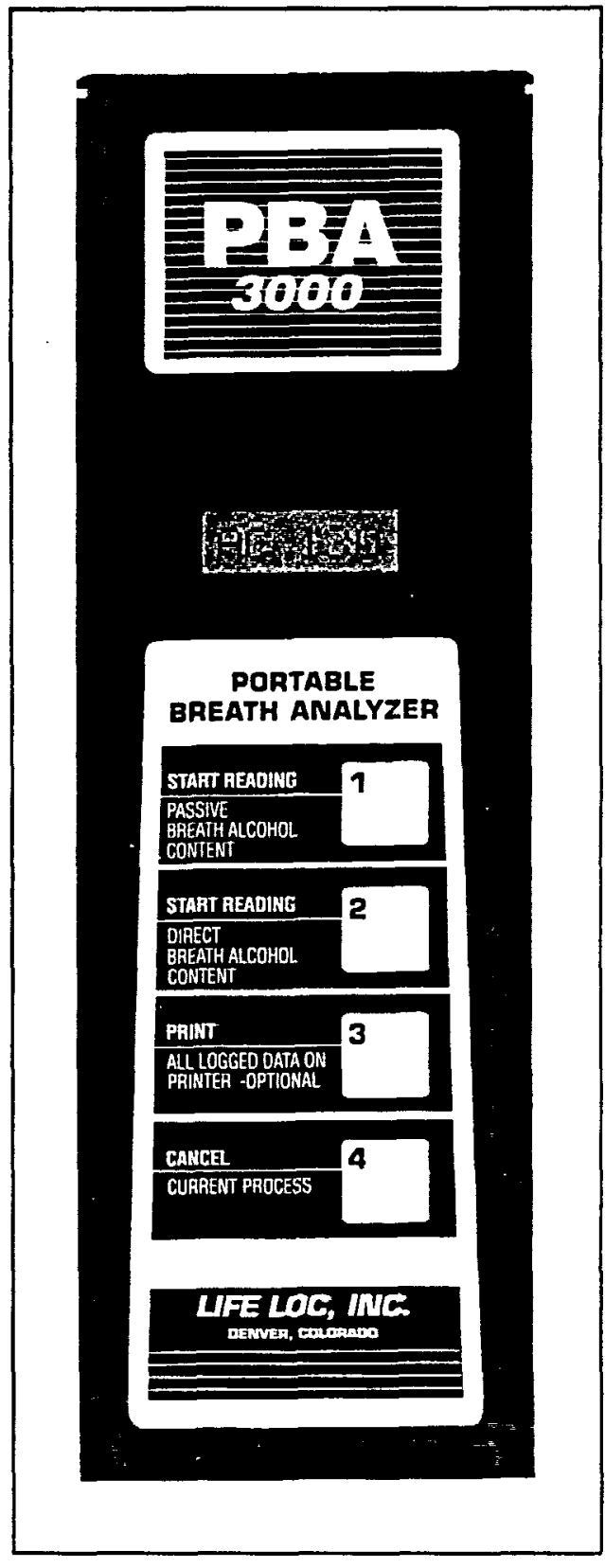

Figure 2. PBA 3000 (Throughout this study the devices were kept on the factory-default 3-digit BAC readings for both passive and direct tests.)

Life Loc also advertises "diagnostics before every reading" and "automated zeroing." One additional feature is that the unit will store the results (time, date, mode (passive or PBT), BAC, and sequence number) for up to 175 readings. Stored data can be downloaded to a PC or 
printer. Life Loc markets a communications program for PCs that can receive, store, and print the data from the PBA 3000.

The PBA 3000 uses eight AA alkaline batteries. When the unit is turned on, an E-F (empty-full) "gas gauge" appears briefly to show how fully charged or discharged the batteries are.

\section{Mark X Alcohol Checker}

The last device is the Mark X Alcohol Checker manufactured by Guth Laboratories, Inc., of Harrisburg, Pennsylvania. This is a very small and relatively inexpensive device, 5.6 inches long and only 1.8 ounces in weight. It does not use fuel cell technology. Rather, the Mark X is based on an "alcohol-selective ceramic semiconductor." Under typical operations, the device is held three inches from the subject and the subject is instructed to blow into it for four to seven seconds; mouthpieces are available to make this a direct test, or subjects can simply blow directly at the port on the front of the device. The Mark X can be used as a passive alcohol sensor by "waving it back and forth in a vehicle" or several inches in front of the subject's mouth.

The Mark X has an off-on switch. When turned on, the unit takes about 10 seconds for a self test; it then measures the alcohol in the ambient air (it has no pump or fan) over the next minute or so. Results are displayed on six LEDs (three yellow and three red) which correspond to BAC levels of $0.00 \%, 0.02 \%, 0.04 \% ; 0.08 \%, 0.10 \%$, and $0.12 \%$ or higher (numbers are printed beside the LEDs, unlike the P.A.S. III, which has no BAC numbers printed on the device itself.) If a $B A C$ value of $0.08 \%$ or higher is reached, the device emits a highpitched beeping sound.

The Mark X uses two AAA alkaline batteries.

For the study, six P.A.S. III units, six PBA 3000 units, and 10 Mark X units were used. For each of the P.A.S. III units, $A C$ and automobile charging units were available. For the PBA 3000s, cables to connect them to printers or to PCs and the Life Loc communications software (to transmit stored data from the devices to PCs) were available.

It should be noted that all of these devices are designed to operate in temperatures no lower than $32^{\circ}$ Fahrenheit $\left(0^{\circ}\right.$ Celsius) nor higher than about $100^{\circ}$ Fahrenheit $\left(38^{\circ}\right.$ Celsius). The Mark X and the Sniffer P.A.S. III may operate better at low temperatures - the Mark X because it is usually carried in the officer's pocket, and the P.A.S. III because it has a fuel cell heater 
which operates when the flashlight is turned on. Nevertheless, ambient temperatures are a significant consideration in the use of this technology.

\section{Identify Sites}

Police agencies were sought in youth zero tolerance states. Agencies were sought that had an interest in youth drinking and driving enforcement and permitted the use of passive sensors. They were sought in mid-size communities that contained a substantial number of young drivers. Three such agencies were identified, one in each of three zero tolerance states, and agreed to participate in the study. Statistical data about the three sites are presented in Table 8; narrative descriptions begin here.

\section{Chandler, Arizona}

\section{Arizona Zero Tolerance}

Arizona has had Zero Tolerance legislation for some time. However, they have only recently established implied consent provisions for Zero Tolerance violations (September 30, 1992). The law is contained in the alcohol section of the Arizona Statutes (4-244 paragraph 34). It makes it unlawful:

For a person under the age of twenty-one years to drive or be in physical control of a motor vehicle while there is any spirituous liquor in the person's body.

\section{Community Description}

Chandler, Arizona, is located twenty-five miles southeast of Phoenix. It has a population of more than 108,000 in a metropolitan area of more than 2.1 million people. It is a suburban community which covers an area of 48 square miles. It is bordered on the south by Indian reservations. Its climate is typical of the southwest with an average annual temperature of 70 degrees and average precipitation of approximately 8.5 inches per year. Winter and spring temperatures tend to be mild, rarely dropping below freezing; summer high temperatures average over $100^{\circ} \mathrm{F}$ and may reach $120^{\circ} \mathrm{F}$ or more. Arizona State University and Mesa Community College are close by.

During the study period, Chandler was experiencing a long period of rapid growth, averaging about 7 percent per year. Affordable housing and an increase in job openings were attracting residents to this area of Arizona. The Maricopa County Association of Governments predicts that Chandler will reach a population of over 150,000 by the year 2000 and 240,000 by 2010. 
Table 8. Site Descriptive Factors

\begin{tabular}{|c|c|c|c|}
\hline Factor & $\begin{array}{l}\text { Chandler, } \\
\text { Arizona }\end{array}$ & $\begin{array}{l}\text { Murfreesboro, } \\
\text { Tennessee }\end{array}$ & $\begin{array}{c}\text { Hamilton Twp., } \\
\text { New Jersey }\end{array}$ \\
\hline $\begin{array}{l}\text { Population: Total } \\
\text { Percent Male } \\
\text { Median Age }\end{array}$ & $\begin{array}{c}108,388(1993) \\
49.6 \% \text { male } \\
28.8 \text { years }\end{array}$ & $\begin{array}{c}47,200(1992) \\
47.6 \% \text { male } \\
28.0 \text { years }\end{array}$ & $\begin{array}{c}86,553(1990) \\
47.8 \% \text { male } \\
36.4 \text { years }\end{array}$ \\
\hline $\begin{array}{l}\text { Land Area } \\
\text { Population Density }\end{array}$ & $\begin{array}{l}47.6 \mathrm{sq} . \mathrm{mi} . \\
1,902 \mathrm{ppl} / \mathrm{sq} \cdot \mathrm{mi} .\end{array}$ & $\begin{array}{l}30.4 \mathrm{sq} . \mathrm{mi} \\
1,478 \mathrm{ppl} / \mathrm{sq} . \mathrm{mi} \text {. }\end{array}$ & $\begin{array}{c}39.4 \mathrm{sq} . \mathrm{mi} . \\
2,197 \mathrm{ppl} / \mathrm{sq} . \mathrm{mi} .\end{array}$ \\
\hline $\begin{array}{l}\text { Race: } \\
\text { White } \\
\text { Black } \\
\text { Native Amer/Eskimo } \\
\text { Asian/Pacific Islander } \\
\text { Other Race } \\
\text { Hispanic (any race) }\end{array}$ & $\begin{array}{l}85.2 \% \\
2.6 \% \\
1.2 \% \\
2.4 \% \\
8.7 \% \\
17.3 \%\end{array}$ & $\begin{array}{l}82.3 \% \\
14.5 \% \\
0.2 \% \\
2.8 \% \\
0.2 \% \\
0.8 \%\end{array}$ & $\begin{array}{l}92.0 \% \\
5.1 \% \\
0.1 \% \\
2.1 \% \\
0.7 \% \\
2.3 \%\end{array}$ \\
\hline $\begin{array}{l}\text { Housing: } \\
\text { Total \# Units } \\
\text { Percent Single Unit } \\
\text { Persons/Household } \\
\text { Percent Owner-Occupied } \\
\text { Median Value (Owner- } \\
\text { Occupied) }\end{array}$ & $\begin{array}{c}34,967 \\
70.4 \% \\
2.86 \\
70.0 \% \\
\$ 90,300\end{array}$ & $\begin{array}{c}18,708 \\
53.7 \% \\
2.38 \\
43.5 \% \\
\$ 78,200\end{array}$ & $\begin{array}{c}33,457 \\
73.7 \% \\
2.64 \\
72.4 \% \\
\$ 135,100\end{array}$ \\
\hline $\begin{array}{l}\text { Education Level: } \\
\text { < High School Grad } \\
\text { High School Graduate } \\
\text { Some College/Assoc. Dgr } \\
\text { B.S./B.A. Degree } \\
\text { Graduate School }\end{array}$ & $\begin{array}{l}15.5 \% \\
22.8 \% \\
38.1 \% \\
17.3 \% \\
6.3 \%\end{array}$ & n.a. & $\begin{array}{l}22.7 \% \\
34.4 \% \\
23.2 \% \\
13.6 \% \\
6.1 \%\end{array}$ \\
\hline Average Income & $\$ 41,800$ & $\$ 32,900$ (county) & $\$ 52,300$ (county) \\
\hline $\begin{array}{l}\text { Police Department: } \\
\text { Sworn Officers } \\
\text { Civilian Employees } \\
\text { Special Units }\end{array}$ & $\begin{array}{l}110 \\
50 \\
\text { Traffic (incl. } 5 \\
\text { motors) } \\
\text { Bicycle (4 } \\
\text { officers) } \\
\text { Gang }\end{array}$ & $\begin{array}{l}\quad 97 \\
25 \\
\text { Normal patrol } \\
\text { with traffic } \\
\text { and DWI } \\
\text { emphasis } \\
\text { M.P.A.C.T. }\end{array}$ & $\begin{array}{l}\quad 180 \\
\quad 28 \\
\text { Traffic } \\
\text { Bicycle (\& } \\
\text { DARE) } \\
\text { Safe Neighbor- } \\
\text { hoods }\end{array}$ \\
\hline
\end{tabular}




\section{Chandler Police Department}

At the beginning of the study, there were approximately 110 sworn officers and 50 civilian employees in the Chandler Police Department. During the study period the department began hiring new officers to increase the total number to approximately 150 . The impact of the new officers on the study was minimal, although occasionally officers who were part of the study were taken from their normal assignments to train the new officers. Civilians operate the planning section (e.g., data analysis) which includes a computer tie-in to municipal court records.

Sensors were deployed by three distinct units of the Department. The first was the Traffic Division, which included five motorcycle officers. The second was a group of officers that patrol downtown areas on bicycles. These officers conduct traffic enforcement and are likely to encounter many young drivers. The third unit was involved with gang intervention. These officers make traffic stops on a regular basis and often encounter young drivers.

From January, 1988, through October, 1993, the period immediately before this field test, the Chandler Police Department averaged 4.6 DWI arrests per month for drivers under the age of 21 and 40.9 DWI arrests per month for drivers ages 21 and older. Over the same time period, the Chandler P.D. made an average of 20.7 arrests per month of persons under the age of 21 for non-driving liquor law violations.

\section{Murfreesboro, Tennessee}

\section{Tennessee .02}

At the time of the study, the Tennessee $.02 \mathrm{BAC}$ law for youth was relatively new. It was signed by the Governor on May 31, 1993, and become effective on July 1, 1993. The effect of the law was to amend Tennessee Code Title 55, Chapter 10, Part 4 by adding the following language:

A person age sixteen (16) or over but under age twenty-one (21) may not drive or be in physical control of an automobile or other motor driven vehicle while:

The alcohol concentration in the person's body is more than two hundredths of one percent $(0.02 \%)$; or

Under the influence of alcohol; or

Under the influence of any intoxicant, marijuana, narcotic drug, or drug producing stimulating effects on the central nervous system; or

Under the combined influence of alcohol and any other diug set out in subsection (a) (1)(C) to a degree which makes the person's driving ability impaired. 


\section{Community Description}

Murfreesboro, Tennessee, is located 30 miles southeast of Nashville in Rutherford County. It is a suburban small city environment, having a population of 47,200 full-time residents on the edge of a metropolitan area of nearly one million. It has an average annual temperature of 58 degrees and average annual precipitation of 58.4 inches. Winter and Spring tend to be mild. It is the home of Middle Tennessee State University with more than 18,000 enrolled students.

General Murfreesboro statistical data are summarized in Table 8. In addition, Rutherford County has 42,118 households ( 61 percent owner occupied); Murfreesboro has an average of 1.6 vehicles per household.

Murfreesboro is changing from an agricultural and labor based community to a technological and business based community. Middle Tennessee State University attracts many young persons. Features making Murfreesboro attractive for this study included comparatively large numbers of young drivers, a mild climate for a winter field test, and, as discussed below, plans to implement a youth alcohol enforcement unit.

\section{Murfreesboro Police Department}

During the study period, the Murfreesboro Police Department had approximately 97 sworn officers plus 25 civilian employees. Traffic duties are integrated into normal patrols rather than being the responsibility of a special unit. Within the patrols, there are several officers who concentrate on DWI. At the time of the study, Murfreesboro was working to establish a special youth alcohol and drug enforcement unit within the Department. The Department coordinates youth enforcement with the Middle Tennessee State University Police officers, who work mostly on campus but who can assist in off-campus calls. They coordinate sobriety checkpoint operations with the Tennessee State Police.

Sensors were deployed with two officers on afternoon patrol and with four officers who concentrate on DWI. Beginning February 1, 1994, the latter group of officers made up the new youth alcohol and drug enforcement unit. This M.P.A.C.T. unit patrolled in three vehicles between $8 \mathrm{pm}$ and $4 \mathrm{am}$. One sobriety checkpoint, while Murfreesboro was testing the Mark X sensors, was conducted in cooperation with the Tennessee State Police.

For January, 1988, through October, 1993 Murfreesboro officers made an average of 4.1 DWI arrests per month for drivers under 21, an average of $34.1 \mathrm{DWI}$ arrests per month for drivers 21 or older. During the same time period, Murfreesboro officers averaged 5.1 arrests per month for non-driving liquor law violations for people under 21. The DWI figures are similar to the values obtained in Chandler; the liquor law violation figures are somewhat lower than the Chandler values. 


\title{
Hamilton Township, New Jersey
}

\author{
New Jersey .01
}

The New Jersey low BAC legislation for youth took effect on December 17, 1992. The language of this law is contained in New Jersey Title 39, Motor Vehicles and Traffic Regulations, section 4-50.14. This paragraph reads as follows:

\begin{abstract}
Any person under the legal age to purchase alcoholic beverages [21] who operates a motor vehicle with a blood alcohol concentration of $0.01 \%$ or more, but less than $0.10 \%$, by weight of alcohol in his blood, shall forfeit his right to operate a motor vehicle over the highways of this state for a period of not less than 30 or more than 90 days beginning on the date he becomes eligible to obtain a license or on the day of conviction, whichever is later, and shall perform community service for a period of not less than 15 or more than 30 days.
\end{abstract}

\section{Community Description}

Hamilton Township is a suburban community located just east of Trenton, the New Jersey state capital. It has more than 86,000 residents in a total metropolitan area of about 300,000 people. Hamilton Township covers 39.4 square miles in Mercer County on the Pennsylvania/New Jersey border. Its climate is relatively mild though winter weather can be extreme. Average daily temperatures during January and February are about 30 degrees increasing to about 70 degrees in June. The greater Trenton metropolitan area, which includes Hamilton Township, has an average of 1.5 vehicles per household.

Hamilton Township is the home of Mercer County Community College. Trenton State University and Rider College are in neighboring towns, and Princeton University is located approximately six miles to the north. Hamilton Police encounter many young drivers due to the location of these four colleges and universities.

\section{Hamilton Township Police}

The Hamilton Police currently have 180 sworn officers plus 28 civilian employees. Their Traffic Division has staggered day/evening shift assignments so as to ensure greater coverage on weekend nights. Patrol Division officers make traffic stops as a regular part of their duties. As in Chandler, Hamilton Township operates a bicycle patrol. The department also has a ten-officer "Safe Neighborhoods" unit which is not unlike the gang or drug intervention units found in other cities.

Sensors were primarily deployed with the Traffic Division and the Safe Neighborhoods Unit. Some units were also used by Patrol officers. During the period of the study, one sobriety checkpoint was conducted at which PBA 3000 devices were deployed.

During the period from January, 1988, through October, 1993, Hamilton Township made an average of 1.4 DWI arrests per month for drivers under 21, $9.5 \mathrm{DWI}$ arrests per month for drivers 21 and older, and 1.1 non-driving liquor law arrests of persons under 21. 


\section{Conduct Field Test}

Each department identified one officer who acted as site coordinator. This person monitored and managed the distribution and use of the passive sensors. With project staff, he was responsible for initially training officers on each device. After project staff left the site, he provided any needed follow-up training, answered questions, made sure the devices were operating properly, scheduled focus group meetings, and monitored and collected officer activity logs and summary reports. The site coordinator also served as the primary contact at the site for the project staff.

Devices were distributed to each department for use during the first half of 1994 according to the schedule shown in Table 9. (The first test period actually lasted approximately 10 weeks, the second about 7 weeks, and the third about 8 weeks.) At the beginning of each period, project staff visited each department and conducted a brief training and orientation session for the officers who would be using the devices. Within the limits of duty assignments and other factors such as special assignments and health problems, the same officers participated throughout all three test periods. Site coordinators also participated in these sessions, and they received additional briefings in device calibration and maintenance.

Table 9. Field Test Schedule

\begin{tabular}{|l||c|c|c|}
\hline \multicolumn{1}{|c|}{ Site } & \multicolumn{3}{c|}{ Test Period } \\
& 1 (Jan - Feb) & 2 (Mar - Apr) & 3 (May - June) \\
\hline \hline Chandler, AZ & PBA 3000 & P.A.S. III & Mark X \\
\hline Murfreesboro, TN & P.A.S. III & Mark X & PBA 3000 \\
\hline Hamilton Twp., NJ & Mark X & PBA 3000 & P.A.S. III \\
\hline
\end{tabular}

At the beginning of the first test period, project staff briefed the officers on the purpose of the project and their roles. They were also given a more extensive introduction to the first passive alcohol sensor which included showing the Insurance Institute for Highway Safety orientation videotape, "Using the Passive Alcohol Sensor." While illustrating a device not exactly like any one in this study, the videotape shows officers approaching vehicles, positioning the sensor at the correct distance, and drawing an air sample while the driver is speaking. For officers who would be using the PBA 3000 units, a second videotape, provided by Life Loc, was also shown. It illustrated use and, for the site coordinator, calibration.

In all training sessions, officers were shown how the devices worked and how to interpret readings on the devices. In particular, it was emphasized that the devices could provide indications of the presence of alcohol, but that the actual reading did not necessarily correctly indicate the exact amount of alcohol present. Factors which limited device accuracy included 
proper positioning of the device, how directly the suspect was breathing toward the device, whether there was any wind or breeze, whether the suspect had alcohol in his or her mouth from recent drinking, and whether there were other sources of alcohol such as open containers or drinking passengers. The officers were given hands-on practice with the devices which continued until the officers were comfortable with their use. The training curriculum, developed specifically for these sessions, is included in Appendix A.

In general, officers were instructed to use the devices as frequently as possible during their normal duties. Such activities included, for example, routine traffic stops, stops of under-21 people whether driving or not, school and civic group presentations, and domestic disturbances. Officers also used them when away at training, off duty at home and at parties, and on other occasions. Officers were instructed to use the PBA 3000 and Mark X devices in the passive mode, although they were provided with mouthpieces for each device so that it was possible to make direct tests as well.

Each department provided additional guidance and instruction on how the devices were to be deployed. For example, Tennessee limits alcohol testing to a single test; Murfreesboro officers were instructed to use all devices strictly in the passive mode until (as appropriate) arrests including evidentiary testing were completed, then to ask subjects to voluntarily participate in the study.

Officers were asked to keep logs summarizing, by shift, their uses of the devices. Basic information for the logs included date, time, officer identification (badge number), number of times used, number of arrests (alcohol vs. non-alcohol, driving vs. non-driving, under 21 vs. 21 and older), and comments. In some cases, log entries were made for each use.

At the end of each test period, officers were asked to write brief reports on how they used the devices, any unusual or noteworthy experiences, good points and bad points of the devices, and how effective and useful they judged the devices to be.

Also, at the end of each test period project staff conducted debriefing focus groups with the officers in each department. They were asked to discuss their duty assignment during the test period, how and how frequently they used the tested device, machine (mechanical) reliability, judged accuracy, overall strengths and weaknesses of the device, and training adequacy. They were also asked about interesting experiences and for their advice to other departments that might be considering the use of such devices.

At the end of the final test period, officers were also asked in their focus groups to compare the three devices for their effectiveness in traffic and non-traffic, under 21 and 21 and older, day and night conditions. They were asked their personal preferences and their recommendations for their departments as a whole.

Table 10 shows the numbers and duty assignments of the officers who were assigned 
p. $\approx$ alcohol sensors. In Chandler, patrol and motorcycle officers also had primary traffic res: nsibility. Bicycle of wers de ait with mostly non-traffic situations in commercial and resicuential areas. The gang officer patrolled a: sight; although emphasizing youth, he also made traffic stops and responded to other calls. In $W$ urfreesboro, traffic responsibilities were important duties for all officers. M.P.A.C.T. officers worked from $8 \mathrm{pm}$ to $4 \mathrm{am}$, initiating stops and serving as backup for other officers. In Hamilton Township, patrol officers as well as traffic officers had a primary responsibility for traffic enforcement. Safe Neighborhoods Unit officers worked days and evenings in specific geographic areas, emphasizing proaction.

Table 10. Duty Assignments of Officers

\begin{tabular}{||l|c|c|c||}
\hline \multicolumn{1}{|c|}{ Primary Duty } & Chandler & Murfreesboro & Hamilton Twp. \\
\hline \hline Traffic & - & - & 4 \\
\hline Patrol & 5 & 2 & 6 \\
\hline Motorcycle & 2 & 1 & 1 \\
\hline Bicycle & 4 & - & - \\
\hline Gang & 1 & - & - \\
\hline M.P.A.C.T. & - & 3 & - \\
\hline Safe Neighborhoods & - & - & 3 \\
\hline
\end{tabular}

\section{Collect Background Information and Statistics}

Along with the field test itself, background information was collected for each site. Two kinds of information were sought. First, for January, 1988, through June, 1994, were data from FBI UCR reports on DWI and non-driving Liquor Law violation arrests. Data were collected by age. Data were collected by month for all except Murfreesboro, where annual summaries for the years 1988 through 1992 were used.

Second, details on DWI arrests of underage drivers for January, 1991, through June, 1994, were sought. Each arrest record and, where available, corresponding adjudication results were tabulated. Specific data items included arrest date and day of week, driver age, sex, and ethnicity, charge(s), BAC, and adjudication result. 


\section{RESULTS}

\section{Use of Passive Alcohol Sensors by Officers}

Officers were requested to keep logs of the times they used the devices. Most of the logs contained one log entry for each use. Some early logs contained single entry lines for each shift which often combine several applications of the devices. For analysis purposes, the shift-summary log entries were converted to one entry per application. These entries did not have exact time of use nor age or sex information about the subjects. They did allow determination of whether alcohol-related or other arrests occurred and included date, day of week, shift, and participating officer.

In some cases, logs were not kept effectively, and a number of passive sensor uses occurred that were not logged. For these, it was generally not possible to know an exact number nor any details of the uses. Interviews suggested that 5-10 uses were lost, on average, for each officer who did not turn in a log for a test period, or a total of about 200 cases for the entire study.

For some cases in which the officers did not log activities while they were using the PBA 3000 , it was possible to use information stored within the device itself to generate usage log entries. These entries included date and time, mode, and measured BAC - but could not provide information about test circumstances, subject characteristics, or contact outcome.

From all these sources of information and inference, then, we conclude that the officers tested the passive sensors at least 1100 times in enforcement situations during this field test. Of these uses, 934 are included in the database. Of entries in the database, about half came from individual log entries, about 45 percent came from shift-summary logs, and about 5 percent came from the PBA 3000 internal memory. These results are summarized in Table 11 and Figure 4.

Overall usage of the devices is best described in terms of the uses documented in the usage database plus the estimates of uses for which logs were not available. Based on those values: Hamilton Township used the passive sensors about 600 times (170 occurrances at one sobriety checkpoint, about 430 uses during other police activities), Chandler used them about 260 times, and Murfreesboro used them about 240 times. The PBA 3000 was used about 450 times (170 times at the checkpoint plus about 280 other uses), and the P.A.S. III and the Mark X were each used about 325 times. Usage was highest during the first test period, with about 560 uses. In the second test period, devices were used about 380 times (168 at the checkpoint, about 210 other). The third test period showed approximately 170 uses. While the first period was somewhat longer than the second and third, this nonetheless represents a substantial decline in usage over time. 
Table 11. Passive Alcohol Sensor Estimated Application Summary ${ }^{1}$

\begin{tabular}{||l|c|r|r|r||}
\hline \multirow{2}{*}{ Test Period } & \multicolumn{2}{|c|}{ Passive Alcohol Sensor } & Total \\
& PBA 3000 & P.A.S. III & Mark X & \\
\hline \hline Test Period 1 & $140 .^{*}$ & 185 & 235 & 560 \\
\hline Test Period 2 & 280 & $6 .^{*}$ & $30^{*}$ & 375 \\
\hline Test Period 3 & $30 *^{*}$ & 75 & $65 .^{*}$ & 170 \\
\hline \hline Total & 450 & 325 & 330 & 1105 \\
\hline
\end{tabular}

* These cells include estimated data where no logs were available.

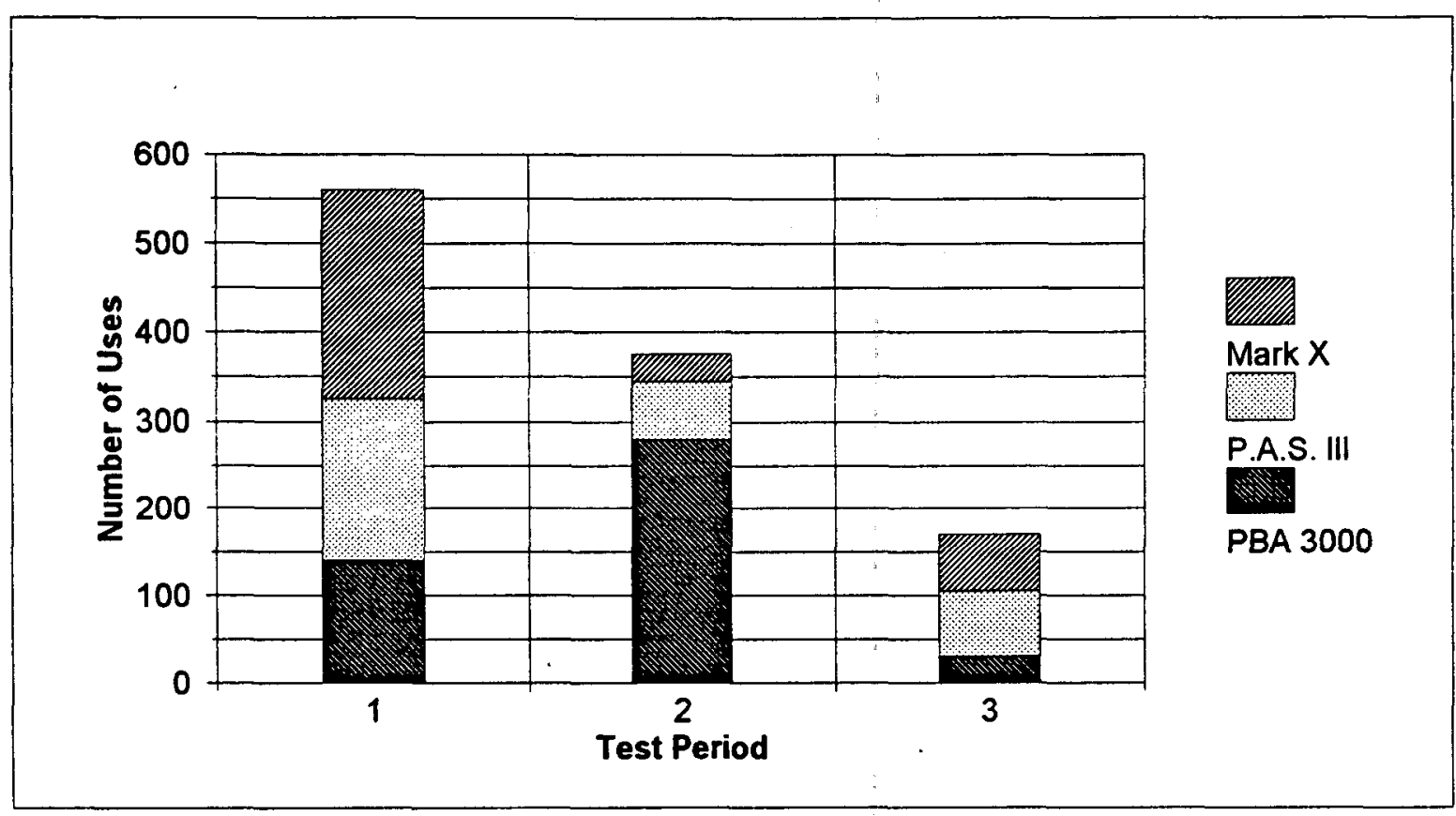

Figure 4. Passive Alcohol Sensor Estimated Applications

All other usage statistics are based on the usage log database of 934 instances. Specific tabulations, because of missing or incomplete data, frequently include fewer subjects. The exact numbers of data points in tabulations are reported in each case.

1 All numbers are approximate. Values for the PBA 3000 during Period 2 include 170 applications at one sobriety checkpoint. Data in cells with estimates may be based on partially complete logs, written summaries from the officers, focus group information, and PBA 3000 internal memory. 
Data on the characteristics of the tested subjects were available for about half of the uses. Drivers made up 83 percent of all tested subjects. Of them, only 16 percent were younger than 21 years of age. Of the non-drivers tested (typically vehicle passengers, pedestrians, or subjects in non-traffic police activity), 67 percent were younger than 21 . Four out of five ( 80 percent) of all tested subjects were male. This held true for drivers and non-drivers regardless of age. Subject characteristics are summarized in Table 12.

Table 12. Subjects on Whom Passive Alcohol Sensors Were Used

\begin{tabular}{||l||c|c|c||}
\hline \multicolumn{1}{|c|}{ Age and Sex } & Drivers & Non-Drivers & Total \\
\hline \hline Under 21 - Male & $10 \%$ & $10 \%$ & $20 \%$ \\
\hline Under 21 - Female & $3 \%$ & $2 \%$ & $5 \%$ \\
\hline Under 21 - Total & $\mathbf{1 3 \%}$ & $\mathbf{1 2 \%}$ & $\mathbf{2 5 \%}$ \\
\hline \hline 21 or Older - Male & $48 \%$ & $3 \%$ & $51 \%$ \\
\hline 21 or Older - Female & $12 \%$ & $2 \%$ & $13 \%$ \\
\hline 21 or Older - Unknown & $10 \%$ & $0.6 \%$ & $11 \%$ \\
\hline 21 or Older - Total & $\mathbf{7 0 \%}$ & $\mathbf{5 \%}$ & $\mathbf{7 5 \%}$ \\
\hline \hline Total & $\mathbf{8 3 \%}$ & $\mathbf{1 7 \%}$ & $\mathrm{N}=463$ \\
\hline \hline
\end{tabular}

Table 13 tabulates uses according to officer duty assignments, usage context (i.e. traffic, checkpoint, or other police), and type of passive sensor. It provides, for each condition, the distribution of passive sensor BAC readings and the proportion of all contacts leading to an alcohol-related arrest. Figures 5 and 6 summarize sensor uses by officer duty assignment and by usage context.

Most uses of the passive alcohol sensors were logged by patrol officers ( 40 percent). They found that 32 percent of their readings showed positive BACs, nearly equally divided into readings of $.049 \%$ and lower (11 percent), $.05 \%$ to $.099 \%$ ( 9 percent), and $.10 \%$ and higher (12 percent). Overall, 21 percent of patrol officer contacts led to alcohol-related arrests.

Traffic officers accounted for 22 percent of sensor uses. The vast majority ( 95 percent) of their readings showed no alcohol present, and 4 percent gave readings of $.10 \%$ or higher. Of traffic officer uses, only 4 percent were associated with alcohol-related arrests.

M.P.A.C.T. unit uses in Murfreesboro and gang officer uses in Chandler were associated with very high percentages of alcohol-related arrests. For M.P.A.C.T. units, although passive 


\begin{tabular}{|c|c|c|c|c|c|c|c|}
\hline & \multirow{2}{*}{ Factor / Values } & \multirow{2}{*}{$\begin{array}{c}\text { Distribu- } \\
\text { tion of } \\
\text { Sensor } \\
\text { Uses }\end{array}$} & \multicolumn{4}{|c|}{ Passive Sensor BAC Readings } & \multirow{2}{*}{$\begin{array}{c}\text { \% Cases } \\
\text { leading to } \\
\text { Alcohol- } \\
\text { Related } \\
\text { Arrests }\end{array}$} \\
\hline & & & $0.00 \%$ & $\begin{array}{l}>0 \%- \\
.049 \%\end{array}$ & $\begin{array}{l}.05 \% \\
.099 \%\end{array}$ & $\begin{array}{l}>= \\
.10 \%\end{array}$ & \\
\hline \multirow[t]{2}{*}{$\begin{array}{c}\text { Officer's } \\
\text { Primary } \\
\text { Duty } \\
\text { Assign- } \\
\text { ment }\end{array}$} & \multirow[t]{2}{*}{\begin{tabular}{|l|} 
Traffic \\
Patrol \\
Motorcycle \\
Safe Neighborhoods (Hamilton \\
Township) \\
M.P.A.C.T. (Murfreesboro) \\
Gangs (Chandler) \\
Checkpoint (Hamilton Township)
\end{tabular}} & $\begin{array}{l}22 \% \\
40 \% \\
3 \% \\
6 \% \\
7 \% \\
3 \% \\
19 \%\end{array}$ & $\begin{array}{l}95 \% \\
68 \% \\
96 \% \\
91 \% \\
72 \% \\
50 \% \\
98 \%\end{array}$ & $\begin{array}{c}1 \% \\
11 \% \\
0 \\
6 \% \\
24 \% \\
38 \% \\
1 \%\end{array}$ & $\begin{array}{c}0 \\
9 \% \\
0 \\
2 \% \\
2 \% \\
4 \% \\
0\end{array}$ & $\begin{array}{l}4 \% \\
12 \% \\
4 \% \\
2 \% \\
2 \% \\
8 \% \\
1 \%\end{array}$ & $\begin{array}{c}4 \% \\
21 \% \\
17 \% \\
9 \% \\
\\
58 \% \\
50 \% \\
1 \%\end{array}$ \\
\hline & & $\mathrm{N}=906$ & \multicolumn{4}{|c|}{$N=862$} & $\mathrm{~N}=906$ \\
\hline \multirow{2}{*}{$\begin{array}{l}\text { Context of } \\
\text { Sensor } \\
\text { Usage }\end{array}$} & \multirow[t]{2}{*}{$\begin{array}{l}\text { Traffic-Related } \\
\text { Checkpoint } \\
\text { Other Police Activity }\end{array}$} & $\begin{array}{l}74 \% \\
19 \% \\
7 \%\end{array}$ & $\begin{array}{l}85 \% \\
98 \% \\
41 \%\end{array}$ & $\begin{array}{l}6 \% \\
1 \% \\
33 \%\end{array}$ & $\begin{array}{c}3 \% \\
0 \\
11 \%\end{array}$ & $\begin{array}{l}6 \% \\
1 \% \\
15 \%\end{array}$ & $\begin{array}{c}17 \% \\
1 \% \\
41 \%\end{array}$ \\
\hline & & $\mathrm{N}=877$ & \multicolumn{4}{|c|}{$\mathrm{N}=833$} & $\mathrm{~N}=877$ \\
\hline \multirow[t]{3}{*}{$\begin{array}{c}\text { Device } \\
\text { and Mode } \\
\text { of } \\
\text { Operation }\end{array}$} & $\begin{array}{l}\text { PBA } 3000 \text { (Checkpoint) } \\
\text { (all passive readings) } \\
\text { PBA } 3000 \text { (Other) ( } 79 \% \text { passive/ } \\
21 \% \text { direct) } \\
\text { P.A.S. III (all passive) } \\
\text { Mark X (86\% passive/14\% } \\
\text { direct) }\end{array}$ & $\begin{array}{l}18 \% \\
25 \% \\
30 \% \\
27 \%\end{array}$ & $\begin{array}{l}98 \% \\
57 \% \\
78 \% \\
91 \%\end{array}$ & $\begin{array}{r}1 \% \\
18 \% \\
13 \% \\
2 \%\end{array}$ & $\begin{array}{c}0 \\
11 \% \\
4 \% \\
1 \%\end{array}$ & $\begin{array}{l}1 \% \\
14 \% \\
5 \% \\
6 \%\end{array}$ & $\begin{array}{l}1 \% \\
18 \% \\
28 \% \\
10 \%\end{array}$ \\
\hline & Total & & $73 \%$ & $12 \%$ & $5 \%$ & $9 \%$ & $16 \%$ \\
\hline & & $N=934$ & \multicolumn{4}{|c|}{$N=890$} & $N=934$ \\
\hline
\end{tabular}




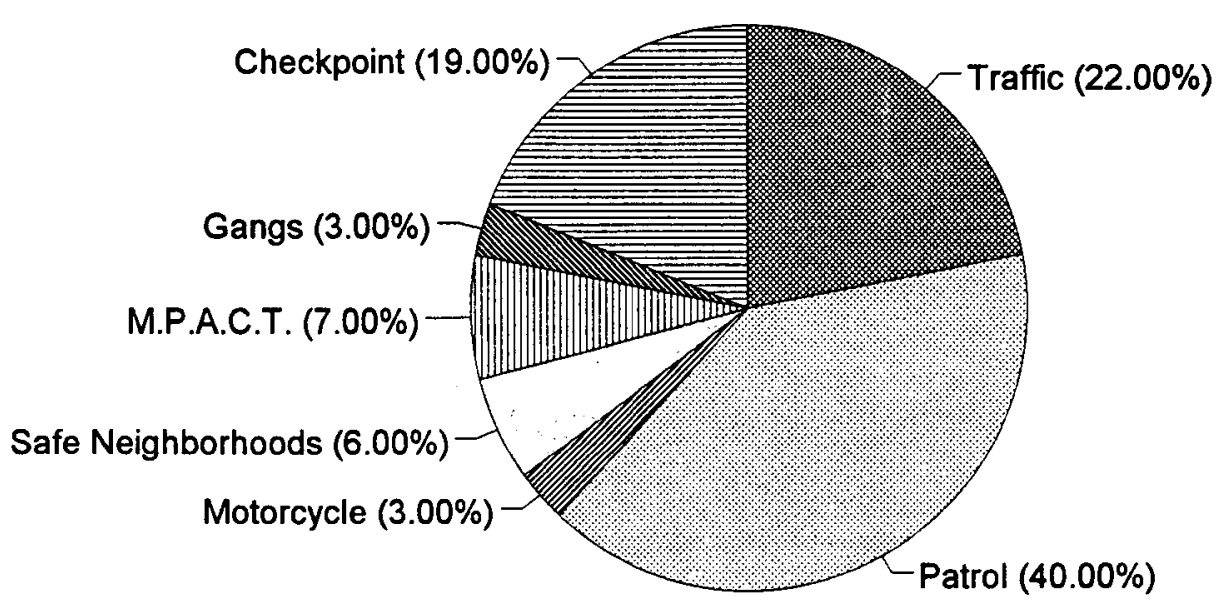

Figure 5. Passive Sensor Use, by Officer Duty Assignment

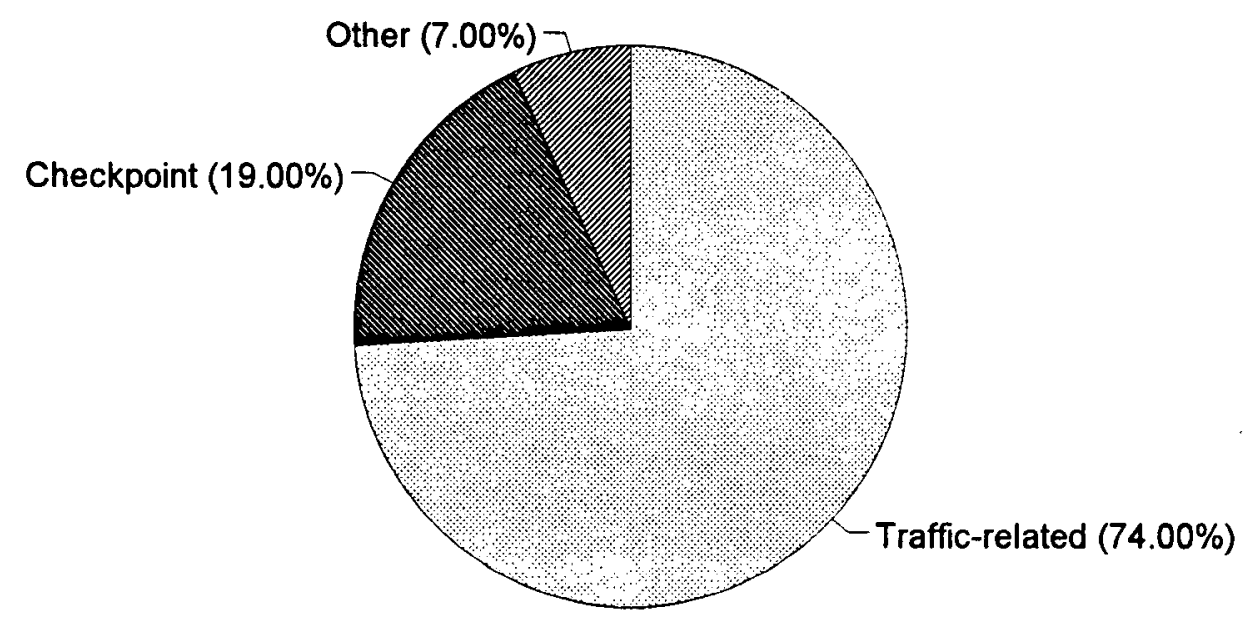

Figure 6. Context of Passive Sensor Use

sensors detected alcohol in just 28 percent of the contacts, 58 percent of all the contacts led to alcohol-related arrests. For Chandler gang officers, 50 percent of the contacts showed positive BACs, and 50 percent of the contacts led to alcohol-related arrests. 
The one checkpoint yielded a single BAC reading of $.10 \%$ or higher, and there was only one alcohol-related arrest at the checkpoint.

The middle of Table 13 shows the incidence of positive $\mathrm{BAC}$ readings and alcohol-related arrests for different kinds of police activity. Traffic-related tests, which accounted for three quarters ( 74 percent) of all contacts, showed positive BAC readings in 15 percent of the contacts and led to alcohol-related arrests in 17 percent of the contacts. "Other police activity" showed positive BAC readings in 59 percent of the contacts, and 41 percent of the contacts led to alcohol-related arrests. These contacts consisted largely of encounters with youth on the streets, other pedestrians, and domestic disturbances. Alcohol-related arrests are illustrated in Figure 7.

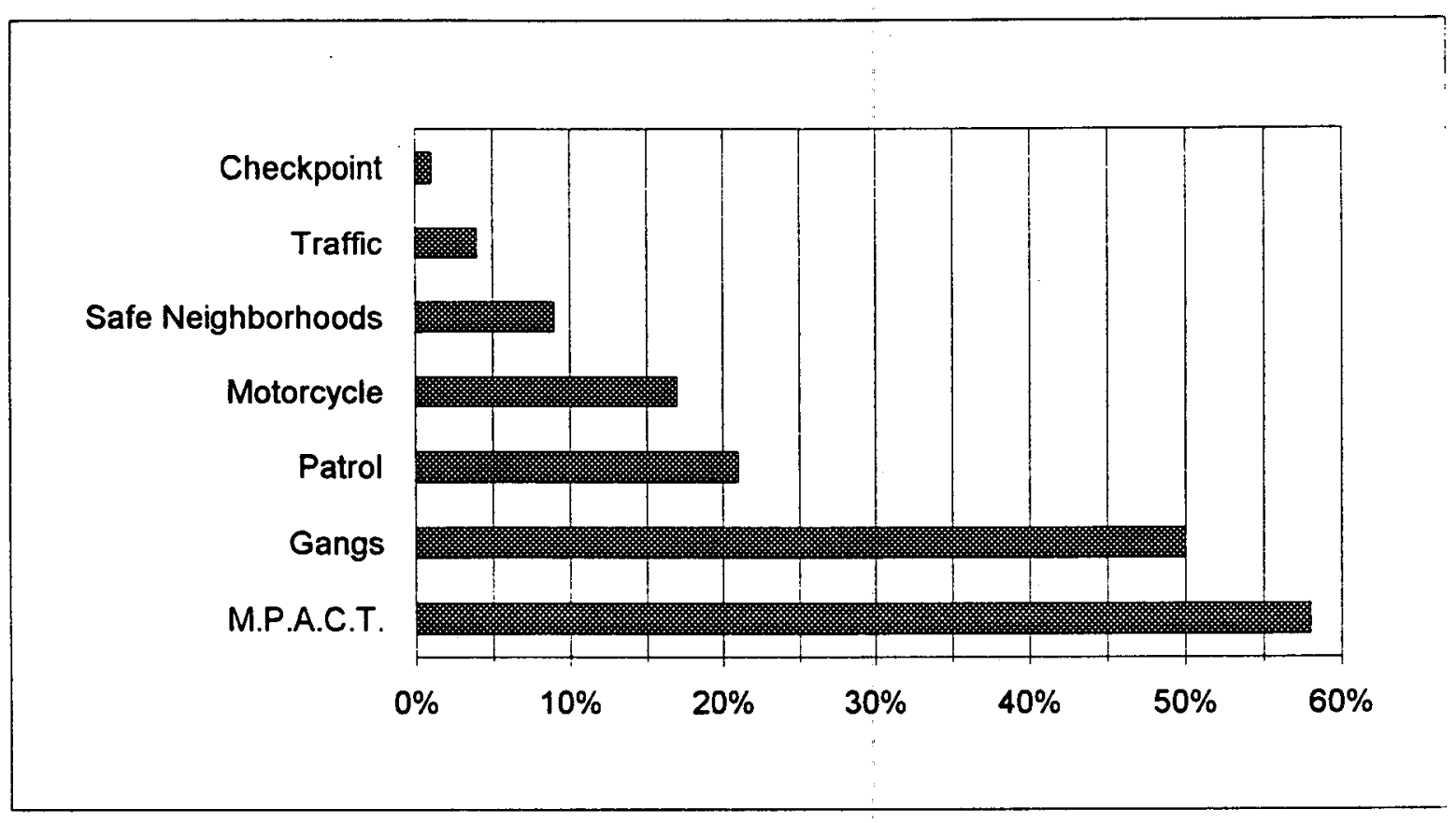

Figure 7. Percent of Contacts Leading to Alcohol-related Arrests

The bottom third of Table 13 compares the three passive alcohol sensors. The PBA 3000 (excluding its use in the checkpoint) gave the highest proportion of positive readings (43 percent), followed by the P.A.S. III ( 22 percent) and the Mark X ( 9 percent). The P.A.S. III was associated with the highest proportion of arrests (28 percent of all contacts).

Objective accuracy of the passive alcohol sensors could not be determined, because results of evidentiary tests were available for only 34 cases. In general, evidentiary BAC readings were higher than those provided by the passive alcohol sensors ( 27 of 34 cases). Evidentiary tests revealed very high BAC levels much more often than did the passive alcohol sensor tests (28 cases at or above $.10 \%$ vs. 16 cases for the passive sensors). In 14 cases, evidentiary tests showed BACs at or above .10\% while passive sensors were below this level; there were only 2 cases in which the reverse was true. 
Values for all uses of passive alcohol sensors are summarized at the bottom of Table 13. Overall, 73 percent of all known passive-sensor BAC readings were zero; 27 percent were $.001 \%$ or higher. Of all the known readings, 4 percent were between $.001 \%$ and the state's zero tolerance limit (the highest values which do not violate zero tolerance are $.009 \%$ in New Jersey and $.02 \%$ in Tennessee; any positive values are above the limit in Arizona). An additional 8 percent were below .05\%; 5 percent were between $.05 \%$ and $.099 \% ; 4$ percent were between $.10 \%$ and $.129 \% ; 1$ percent were between $.13 \%$ and $.149 \%$; and 4 percent were at or above .15\% BAC. (Note that maximum scale values were $.20 \%$ for the PBA $3000, .12 \%$ for the P.A.S. III, and $.15 \%$ for the Mark X.)

For the PBA 3000 and the Mark X, for which direct-mode breath testing was possible, officers used direct-mode tests 21 percent of the time and 14 percent of the time, respectively. In general, officers used the direct mode at the end of interview or arrest sequences or when they were reasonably certain alcohol was present. Thus many more direct-mode tests ( 91 percent) showed BAC levels above zero. However, looking only at tests giving positive BACs, the distributions of BAC levels for passive and for direct tests were quite similar.

Overall, 16 percent of all contacts for which passive alcohol sensors were used resulted in alcohol-related arrests. Again, these could include DWI, zero tolerance, or alcohol law violations.

The distribution of tests across time and day of week is shown in Table 14 for the cases for which time of day was logged (excluding checkpoint data). One quarter ( 26 percent) of all tests were done between Saturday at $8 \mathrm{pm}$ and Sunday morning before $4 \mathrm{am}$. The next-highest

Table 14. Time and Day of Sensor Usage (Excluding Checkpoint Data)

\begin{tabular}{||c||c|c|c|c|c|c|c|c||}
\hline & Mon & Tues & Wed & Thurs & Fri & Sat & Sun & Total \\
\hline \hline Mid - 3:59 am & $2 \%$ & $2 \%$ & 0 & $4 \%$ & $3 \%$ & $6 \%$ & $14 \%$ & $30 \%$ \\
\hline $\mathbf{4}$ am - 7:59 am & 0 & $2 \%$ & 0 & 0 & $0.3 \%$ & $0.3 \%$ & $0.3 \%$ & $2 \%$ \\
\hline 8 am - 11:59 am & $0.5 \%$ & 0 & $1 \%$ & $2 \%$ & $0.8 \%$ & 0 & 0 & $4 \%$ \\
\hline Noon - 3:59 pm & $2 \%$ & $0.5 \%$ & $0.5 \%$ & $3 \%$ & $0.8 \%$ & 0 & 0 & $7 \%$ \\
\hline 4 pm - 7:59 pm & $0.8 \%$ & $2 \%$ & $0.3 \%$ & $4 \%$ & $3 \%$ & $3 \%$ & $2 \%$ & $16 \%$ \\
\hline 8 pm - 11:59 pm & $3 \%$ & $6 \%$ & $5 \%$ & $6 \%$ & $6 \%$ & $12 \%$ & $3 \%$ & $41 \%$ \\
\hline \hline Total & $8 \%$ & $12 \%$ & $7 \%$ & $19 \%$ & $13 \%$ & $21 \%$ & $20 \%$ & $\mathrm{~N}=378$ \\
\hline
\end{tabular}


period, with 12 percent of all tests, was between Friday at $8 \mathrm{pm}$ and Saturday before 4 am. Thursday, Saturday, and Sunday each accounted for about one-fifth of all tests. By time of day, most tests (41 percent) were done between $8 \mathrm{pm}$ and midnight, 30 percent were done between midnight and $4 \mathrm{am}$, and another 16 percent were done in the early evening from $4 \mathrm{pm}$ to $8 \mathrm{pm}$.

For combined time periods, Table 15 shows BAC levels registered by the passive sensors and the percent of contacts resulting in alcohol-related arrests. For Thursday, Friday, and Saturday from $8 \mathrm{pm}$ until 4 am the next morning, approximately half of all tests showed positive BACs; one out of three was at $.05 \%$ or above; and one out of five was at $.10 \%$ or above. The same time periods on the other days of the week showed similar patterns: 49 percent of the tests showed positive BACs; 22 percent were $.05 \%$ or higher; and 13 percent were $.10 \%$ or higher. Across all days from $8 \mathrm{pm}$ to $4 \mathrm{am}$, approximately one quarter of all contacts resulted in alcoholrelated arrests.

Table 15. Day and Time Periods and Passive Alcohol Sensor Use

\begin{tabular}{|c|c|c|c|c|c|c|}
\hline \multirow{2}{*}{$\begin{array}{c}\text { Time of Day and Day of } \\
\text { Week Periods }\end{array}$} & \multirow{2}{*}{$\begin{array}{l}\text { Distri- } \\
\text { bution } \\
\text { of } \\
\text { Sensor } \\
\text { Uses }\end{array}$} & \multicolumn{4}{|c|}{$\begin{array}{c}\text { Passive Sensor BAC } \\
\text { Readings }\end{array}$} & \multirow{2}{*}{$\begin{array}{c}\% \text { Cases } \\
\text { Leading } \\
\text { to } \\
\text { Alcohol- } \\
\text { Related } \\
\text { Arrests }\end{array}$} \\
\hline & & $0.00 \%$ & $\begin{array}{l}>0 \%= \\
.049 \%\end{array}$ & $\begin{array}{l}.05 \% \\
.099 \%\end{array}$ & $\begin{array}{l}>= \\
.10 \%\end{array}$ & \\
\hline Thurs 8 pm - Fri 3:59 am & $6 \%$ & $41 \%$ & $27 \%$ & $15 \%$ & $18 \%$ & $26 \%$ \\
\hline Fri 8 pm - Sat 3:59 am & $8 \%$ & $53 \%$ & $14 \%$ & $14 \%$ & $19 \%$ & $21 \%$ \\
\hline Sat $8 \mathrm{pm}$ - Sun 3:59 am & $17 \%$ & $52 \%$ & $13 \%$ & $14 \%$ & $21 \%$ & $30 \%$ \\
\hline Other days, $8 \mathrm{pm}-3: 59 \mathrm{am}$ & $18 \%$ & $51 \%$ & $27 \%$ & $9 \%$ & $13 \%$ & $23 \%$ \\
\hline 4 pm - 7:59 pm, all days & $11 \%$ & $75 \%$ & $12 \%$ & 0 & $13 \%$ & $15 \%$ \\
\hline 4 am - 3:59 pm, all days & $9 \%$ & $88 \%$ & $6 \%$ & 0 & $6 \%$ & $16 \%$ \\
\hline \multirow[t]{2}{*}{$\begin{array}{l}\text { Checkpoint (Hamilton } \\
\text { Township) }\end{array}$} & $30 \%$ & $98 \%$ & $1 \%$ & 0 & $1 \%$ & $1 \%$ \\
\hline & $N=552$ & \multicolumn{4}{|c|}{$N=549$} & $\mathrm{~N}=552$ \\
\hline
\end{tabular}

While Tables 13 and 15 include both BAC distributions and alcohol-related arrest statistics, they do not compare them on a case-by-case basis. Table 16 shows this relationship. 
Table 16. Percent of Contacts Resulting in Alcohol-Related Arrests

\begin{tabular}{|c|c|c|c|c|}
\hline \multirow{2}{*}{$\begin{array}{c}\text { Passive } \\
\text { Alcohol Sensor } \\
\text { BAC Readings }\end{array}$} & \multicolumn{3}{|c|}{ Ages of Subjects } & \multirow{2}{*}{ Total } \\
\hline & Under 21 & 21 or older & Unknown & \\
\hline Zero & $\begin{array}{c}14 \% \\
(\mathrm{n}=70)\end{array}$ & $\begin{array}{c}3 \% \\
(\mathrm{n}=113)\end{array}$ & $\begin{array}{c}4 \% \\
(\mathrm{n}=363)\end{array}$ & $\begin{array}{c}5 \% \\
(\mathrm{n}=546)\end{array}$ \\
\hline $.001 \%-.049 \%$ & $\begin{array}{c}67 \% \\
(\mathrm{n}=15)\end{array}$ & $\begin{array}{c}37 \% \\
(\mathrm{n}=30)\end{array}$ & $\begin{array}{c}33 \% \\
(\mathrm{n}=33)\end{array}$ & $\begin{array}{c}41 \% \\
(\mathrm{n}=78)\end{array}$ \\
\hline $.05 \%-.099 \%$ & $\begin{array}{c}67 \% \\
(\mathrm{n}=9)\end{array}$ & $\begin{array}{c}33 \% \\
(n=15)\end{array}$ & $\begin{array}{c}25 \% \\
(n=12)\end{array}$ & $\begin{array}{c}39 \% \\
(\mathrm{n}=36)\end{array}$ \\
\hline $.10 \%$ or higher & $\begin{array}{c}100 \% \\
(\mathrm{n}=8)\end{array}$ & $\begin{array}{c}79 \% \\
(n=33)\end{array}$ & $\begin{array}{c}29 \% \\
(\mathrm{n}=21)\end{array}$ & $\begin{array}{c}65 \% \\
(\mathrm{n}=62)\end{array}$ \\
\hline Total & $\begin{array}{c}\text { 33\% } \\
(\mathrm{n}=102)\end{array}$ & $\begin{array}{c}24 \% \\
(\mathrm{n}=191)\end{array}$ & $\begin{array}{c}8 \% \\
(\mathrm{n}=429)\end{array}$ & $\begin{array}{c}16 \% \\
(\mathrm{n}=722)\end{array}$ \\
\hline
\end{tabular}

Although the numbers of cases in most cells of the table are small and the percentages are therefore quite variable, it is clear that subjects who give higher BAC readings on the passive sensors are much more likely to be arrested on an alcohol-related charge. At all BAC levels, subjects under 21 years of age are more likely to be arrested (as drivers, they can be arrested for zero tolerance law violations; whether or not driving, they can be arrested for liquor law violations). Subjects 21 or older are rarely arrested if their BAC is zero, are arrested about one third of the time when their passive-sensor BAC is positive and below .10\%, and are arrested about four times out of five if their $\mathrm{BAC}$ is $.10 \%$ or higher. The pattern for subjects whose age is not known is much like the pattern for subjects over 21, except for a low arrest rate of 29 percent for BACs at or above $.10 \%$; this suggests that most of the subjects for whom age is unknown are, in fact, 21 or older.

Non-drivers made up a small proportion of all the passive alcohol sensor uses, but when they were tested, high BACs and alcohol-related arrests were much more likely. Table 17 shows the relationship clearly. Overall, when drivers were tested, alcohol-related arrests occurred just 13 percent of the time. When non-drivers were tested, alcohol-related arrests occurred 37 percent of the time. This is primarily because - when officers tested non-drivers - they found alcohol present much more often. However, it is also the case that officers depended much less on the reported $\mathrm{BAC}$ when deciding whether to arrest non-drivers. Twenty-three percent of non-drivers with zero BAC were still arrested for alcohol-related offenses (all were younger than 21 ), much higher than the rate for drivers. Also, only 49 percent of non-drivers with positive BACs were given alcohol-related citations; although youth were cited, non-drivers age 21 or older were very often not cited. 
Table 17. Likelihood of Alcohol-Related Arrest

\begin{tabular}{||l|c|c||}
\hline & Drivers & Non-Drivers \\
\hline \hline Percent with BAC > 0 & $19 \%$ & $52 \%$ \\
\hline $\begin{array}{l}\text { Percent With Alcohol- } \\
\text { Related Arrest if ... }\end{array}$ & & \\
BAC = 0 & $1.3 \%$ & $23 \%$ \\
BAC > 0 & $65 \%$ & $49 \%$ \\
\hline Total Percent with Alcohol- & $13 \%$ & $37 \%$ \\
Related Arrest & & $\mathrm{N}=82$ \\
\hline
\end{tabular}

\section{Underage DWI Arrest Records}

A search of the police and court records in the three sites yielded a total of 392 underage DWI arrest and adjudication records for January, 1991, through June, 1994. One hundred three (26 percent) were from Chandler, 251 (64 percent) were from Murfreesboro, and 38 (10 percent) were from Hamilton Township. Nearly one-third of arrestees were 20 years old (33 percent), followed closely by 19 year olds ( 29 percent) and 18 year olds ( 27 percent). Only 8 percent were age 17 , and only 4 percent were age 16 or younger. On average, arrestees were somewhat older in Murfreesboro (18.9 years old) than in Hamilton Township (18.6) or Chandler (18.5) $(\mathrm{F}=6.78$, d.f. $=2,389 ; \mathrm{p}=.001$ ).

Most of the underage DWI arrests occurred on Friday, Saturday, and Sunday ( 24 percent, 23 percent, and 21 percent respectively). Fewest arrests occurred on Monday (8 percent), Tuesday (6 percent), and Wednesday ( 7 percent). Arrests on Thursday (11 percent) were intermediate. Patterns were not significantly different across sites $\left(\chi^{2}=13.71\right.$, d.f. $\left.=12\right)$. Seven out of eight arrestees were male. This also did not differ across sites $\left(\chi^{2}=0.41\right.$, d.f. $\left.=2\right)$.

The distribution of DWI arrests over time, by site, is shown in Table 18 and graphed in Figure 8. Although levels of arrest were quite different between sites, there were no consistent differences in the time pattern across site $\left(\chi^{2}=14.12\right.$, d.f. $\left.=12\right)$. Chandler and Hamilton Township arrests remained at nearly constant levels throughout the period from 1991 through June 1994. Murfreesboro arrests showed a dramatic increase in the last two six-month periods (from an average of 30 to an average of 51 arrests per period) $\left(\chi^{2}=26.91\right.$, d.f. $=6$; $\left.p<.001\right)$, but the largest value was in the six months before the field test of the passive alcohol sensors. 
Table 18. DWI Arrests from Court Records, by Site and 6-Month Period

\begin{tabular}{||l||c|c|c||c||}
\hline \multicolumn{1}{|c|}{ Time Period } & Chandler & Murfreesboro & Hamilton Twp. & Total \\
\hline \hline Jan. - June 1991 & 10 & 19 & 3 & 32 \\
\hline July - Dec. 1991 & 13 & 39 & 7 & 59 \\
\hline Jan. - June 1992 & 16 & 28 & 5 & 49 \\
\hline July - Dec. 1992 & 17 & 36 & 4 & 57 \\
\hline Jan. - June 1993 & 16 & 27 & 8 & 51 \\
\hline July - Dec. 1993 & 11 & 57 & 8 & 76 \\
\hline \hline $\begin{array}{l}\text { 6 Mos. Avg., } \\
\text { 1991 - 1993 }\end{array}$ & 13.8 & 34.3 & 5.8 & 54.0 \\
\hline \hline Jan. - June 1994 & $\mathbf{2 0}$ & $\mathbf{4 5}$ & $\mathbf{3}$ & $\mathbf{6 8}$ \\
\hline \hline Total & $\mathbf{1 0 3}$ & $\mathbf{2 5 1}$ & $\mathbf{3 8}$ & $\mathbf{3 9 2}$ \\
\hline
\end{tabular}

Adjudication results were found for 308 of the cases. Overall, 183 (47 percent of all cases) pled or were found guilty of DWI, 88 (22 percent) pled or were found guilty of a lesser charge, and 37 ( 9 percent) had the charges dismissed or were found not guilty. Lesser charges included offenses such as reckless driving and minor consuming alcohol as well as driving while impaired. Instances of pleading to the underage zero tolerance law were not observed. Eightyfour cases (21 percent) had unknown adjudication outcomes as of the time data were collected. These included cases where the defendant failed to appear in court, cases transferred to another court (e.g., juvenile or family court) where records are not available, and, particularly for recent cases, ones with future court appearance dates. Most of the lesser charges outcomes were from Murfreesboro, and most of those were in the last year of data collection (half in the six months preceding the field study and half in the six months of the passive alcohol sensor deployment).

The distribution of adjudication outcomes can be seen, by site, in Table 19. The patterns in adjudication outcomes over six-month periods from January, 1991, through June, 1994, are shown in Table 20. Although the patterns of outcomes vary significantly over time (overall $\chi^{2}=$ 58.52 , d.f. $=18 ; \mathrm{p}<.001$ ), they are attributable to increased numbers of unresolved cases in the recent time periods and to the increase in Guilty - Reduced Charge results in the two most recent time periods. That is, there do not appear to be meaningful differences in the pattern of results which are attributable to the passive alcohol sensor test. 


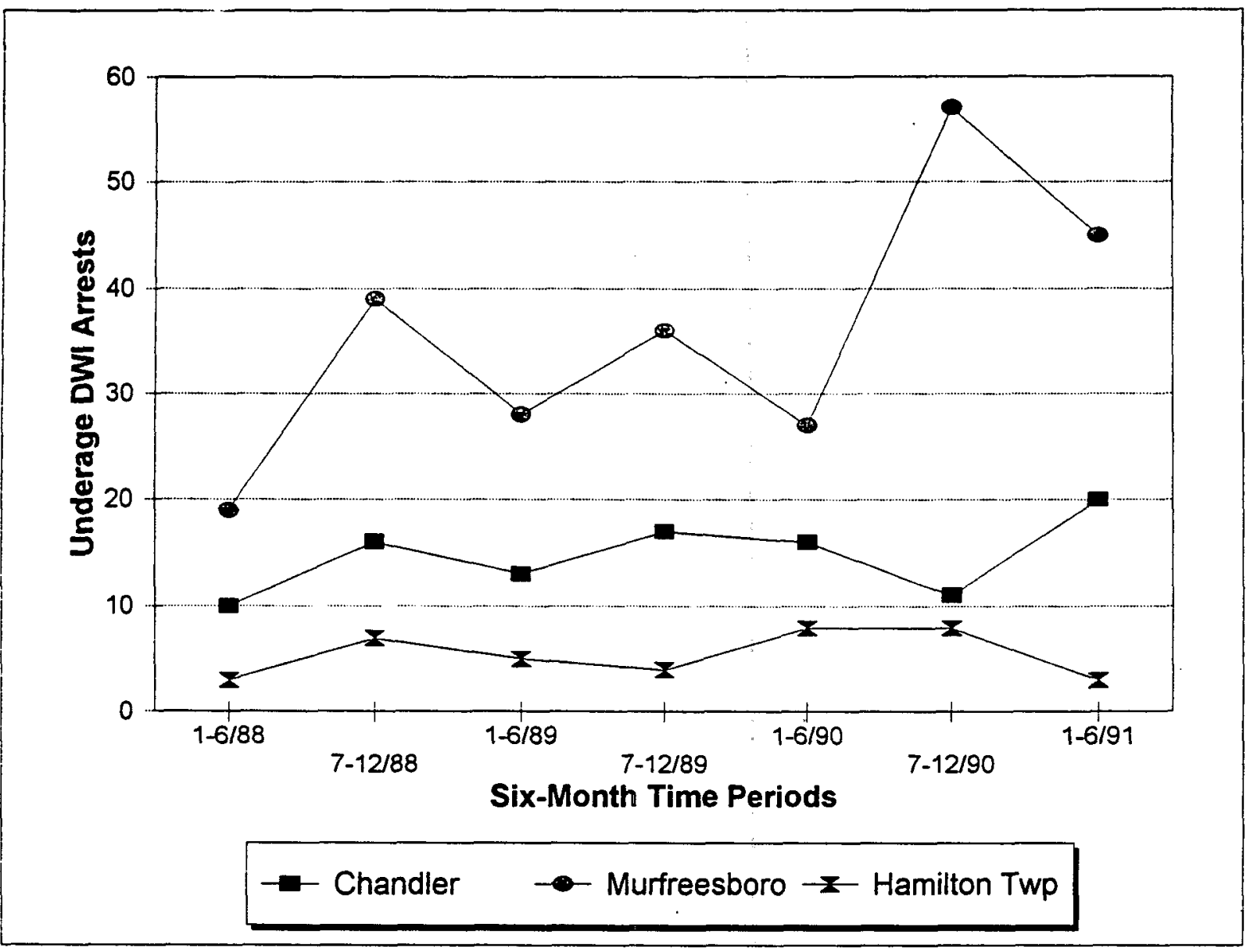

Figure 8. Underage DWI Arrests, Site by Time Period

Table 19. Adjudication Results for Underage DWI Arrests, 1/91 - 6/94, by Site

\begin{tabular}{||l||rr|rr|rr||rr||}
\hline \multicolumn{1}{|c|}{ Results } & Chandler & \multicolumn{2}{|c|}{$\begin{array}{c}\text { Murfrees- } \\
\text { boro }\end{array}$} & \multicolumn{2}{c|}{$\begin{array}{c}\text { Hamilton } \\
\text { Twp. }\end{array}$} & \multicolumn{2}{|c|}{ Total } \\
\hline \hline Guilty, DWI & 50 & $13 \%$ & 110 & $28 \%$ & 23 & $6 \%$ & 183 & $47 \%$ \\
\hline Guilty, reduced charge & 9 & $2 \%$ & 76 & $19 \%$ & 3 & $1 \%$ & 88 & $22 \%$ \\
\hline Not guilty/Dismissed & 7 & $2 \%$ & 24 & $6 \%$ & 6 & $2 \%$ & 37 & $9 \%$ \\
\hline FTA/Future/Unknown & 37 & $9 \%$ & 41 & $10 \%$ & 6 & $2 \%$ & 84 & $21 \%$ \\
\hline \hline Total & 103 & $26 \%$ & 251 & $64 \%$ & 38 & $10 \%$ & 392 & $100 \%$ \\
\hline
\end{tabular}


Table 20. Adjudication Results for Underage DWI Arrests, by 6-Month Period

\begin{tabular}{|c|c|c|c|c|c|}
\hline Time Period & $\begin{array}{c}\text { Guilty, } \\
\text { DWI }\end{array}$ & $\begin{array}{l}\text { Guilty, } \\
\text { Reduced } \\
\text { Charge }\end{array}$ & $\begin{array}{c}\text { Not } \\
\text { Guilty/ } \\
\text { Dismissed }\end{array}$ & $\begin{array}{c}\text { FTA/ } \\
\text { Future/ } \\
\text { Unknown }\end{array}$ & Total \\
\hline Jan. - June 1991 & 21 & 2 & 4 & 5 & 32 \\
\hline July - Dec. 1991 & 36 & 11 & 5 & 7 & 59 \\
\hline Jan. - June 1992 & 25 & 9 & 8 & 7 & 49 \\
\hline July - Dec. 1992 & 35 & 6 & 6 & 10 & 57 \\
\hline Jan. - June 1993 & 24 & 8 & 6 & 13 & 51 \\
\hline July - Dec. 1993 & 22 & 27 & 8 & 19 & 76 \\
\hline $\begin{array}{l}6 \text { Mos. Avg., } \\
1991 \text { - } 1993\end{array}$ & 27.2 & 10.5 & 6.2 & 10.2 & 54.0 \\
\hline Jan. - June 1994 & 20 & 25 & $\mathbf{0}$ & 23 & 68 \\
\hline Total & 183 & 88 & 37 & 84 & 392 \\
\hline
\end{tabular}

$\mathrm{BAC}$ values were known for 309 of the underage DWI arrests. The average BAC for all underage DWI arrests was $.15 \%$, well above the legal limit for adults. Average BAC values were higher in Chandler $(.16 \%)$ and Murfreesboro $(.15 \%)$ than in Hamilton Township $(.09 \%)(\mathrm{F}=$ 16.25 , d.f. $=2,306 ; \mathrm{p}<.001$ ). In Chandler and Murfreesboro, average BAC values dropped gradually from the first half of 1991 to the first half of 1994. Hamilton Township figures, based on just 29 cases in all, show a sharp drop to the middle of the data period and an equally sharp rise to the end. Figures are shown in Table 21. 
Table 21. Average BAC Values for Underage DWI Arrests, by Site and 6-Month Period

\begin{tabular}{||c|c|c|c|c|}
\hline Time Period & Chandler & Murfreesboro & Hamilton Twp. & Total \\
\hline \hline Jan. - June 1991 & $.17 \%$ & $.16 \%$ & $.14 \%$ & $.16 \%$ \\
\hline July - Dec. 1991 & $.18 \%$ & $.16 \%$ & $.11 \%$ & $.16 \%$ \\
\hline Jan. - June 1992 & $.17 \%$ & $.15 \%$ & $.07 \%$ & $.15 \%$ \\
\hline July - Dec. 1992 & $.16 \%$ & $.15 \%$ & $.04 \%$ & $.15 \%$ \\
\hline Jan. - June 1993 & $.15 \%$ & $.13 \%$ & $.08 \%$ & $.13 \%$ \\
\hline July - Dec. 1993 & $.15 \%$ & $.13 \%$ & $.11 \%$ & $.13 \%$ \\
\hline \hline $\begin{array}{l}6 \text { Mos. Avg., } \\
\text { 1991 - 1993 }\end{array}$ & $.16 \%$ & $.15 \%$ & $.09 \%$ & $.15 \%$ \\
\hline \hline Jan. - June 1994 & $.14 \%$ & $.14 \%$ & $.13 \%$ & $.14 \%$ \\
\hline \hline Total & $.16 \%$ & $.15 \%$ & $.09 \%$ & $.15 \%$ \\
\hline
\end{tabular}

BAC levels and adjudication results were closely related. At BACs below .10\%, 17 percent of the cases were found guilty of DWI and 46 percent were found not guilty or dismissed. At BACs from $.10 \%$ to $.129 \%$, above but close to the legal limit for adult drivers, 52 percent were found guilty of DWI and only 6 percent were found not guilty or dismissed. At or above $.13 \%$ BAC, 74 percent were found guilty of DWI while 5 percent were found not guilty or dismissed. (All percentages based on cases with known outcomes.) These results are shown in Table 22.

Table 22. Adjudication Results for Underage DWI Arrests, by BAC Category

\begin{tabular}{|l||c|c|c|c|c||}
\hline BAC Category & $\begin{array}{c}\text { Guilty, } \\
\text { DWI }\end{array}$ & $\begin{array}{c}\text { Guilty, } \\
\text { Reduced } \\
\text { Charge }\end{array}$ & $\begin{array}{c}\text { Not } \\
\text { Guilty/ } \\
\text { Dismissed }\end{array}$ & $\begin{array}{c}\text { FTA/ } \\
\text { Future/ } \\
\text { Unknown }\end{array}$ & Total \\
\hline \hline 0\% - .099\% & 8 & 18 & 22 & 8 & 56 \\
\hline $.10 \%-.129 \%$ & 16 & 13 & 2 & 9 & 40 \\
\hline $.13 \%$ and higher & 126 & 37 & 8 & 42 & 213 \\
\hline Unknown & 33 & 20 & 5 & 25 & 83 \\
\hline \hline Total & 183 & 88 & 37 & 84 & 392 \\
\hline
\end{tabular}




\section{Underage Liquor Law Violations}

The numbers of liquor law arrests of people under age 21 were obtained from FBI UCR reports. Data were collected for 1988 through June 1994. The data were provided as monthly totals, except that Murfreesboro data for 1988 through 1992 were available only as annual totals. The data are summarized by six-month periods in Table 23 and in Figure 9.

The number of underage liquor law arrests varied significantly between sites. Chandler had the highest number, averaging 20.9 arrests per month. In Murfreesboro, there were about 6.2 arrests per month. In Hamilton Township, the average was 1.0 arrests per month.

In all of the sites, underage liquor law arrests showed patterns during the test period that are consistent with the preceding periods. In Chandler, the data showed a peak at the end of 1990 and, otherwise, a gradual increase over the entire period of data reporting. Each January June period showed somewhat fewer arrests than the preceding July - December period. Arrests in the first six months of 1994 followed those patterns. Murfreesboro showed a large increase, from a monthly average of about 4.7 arrests for 1988 through June 1993 to a monthly average of more than 14.2 arrests, for the six months preceding the study and the six months of the study. Because only annual statistics were available through 1992, it was not possible to estimate seasonal variations in Murfreesboro. In Hamilton Township there were no underage liquor law arrests during the six months when the passive sensors were in use. Although at the low end, this is comparable to the numbers of arrests from 1991 through 1993. 


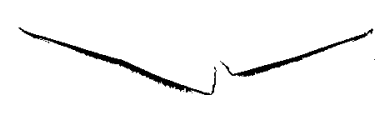

Table 23. Underage uor Law Violations, by Site and 6-Month Period

\begin{tabular}{|c|c|c|c|c|}
\hline Time Period & Chandier & Murfreesboro & Hamilton Twp. & Total \\
\hline Jan. - June 1988 & 93 & \multirow{2}{*}{$72^{* *}$} & 0 & 129 \\
\hline Juiy - Dec. 1988 & 116 & & 0 & 152 \\
\hline Jan. - June 1989 & 77 & \multirow{2}{*}{76} & 7 & 122 \\
\hline July - Dec. 1989 & 117 & & 10 & 165 \\
\hline Jan. - June 1990 & 105 & \multirow{2}{*}{51} & 16 & 147 \\
\hline July - Dec. 1990 & 193 & & 28 & 246 \\
\hline Jan. - June 1991 & 152 & \multirow{2}{*}{33} & 5 & 174 \\
\hline July - Dec. 1991 & 121 & & 0 & 137 \\
\hline Jan. - June 1992 & 99 & \multirow{2}{*}{60} & 0 & 129 \\
\hline July - Dec. 1992 & 132 & & 4 & 166 \\
\hline Jan. - June 1993 & 126 & 21 & 4 & 151 \\
\hline July - Dec. 1993 & 152 & 92 & 5 & 249 \\
\hline Jan. - June 1994 & 145 & 79 & 0 & 224 \\
\hline Total & 1628 & 484 & 79 & 2191 \\
\hline
\end{tabular}

* Totals reflect Murfreesboro data split equally between the first half and second half of 1998 through 1992.

* Based on 10 months data 


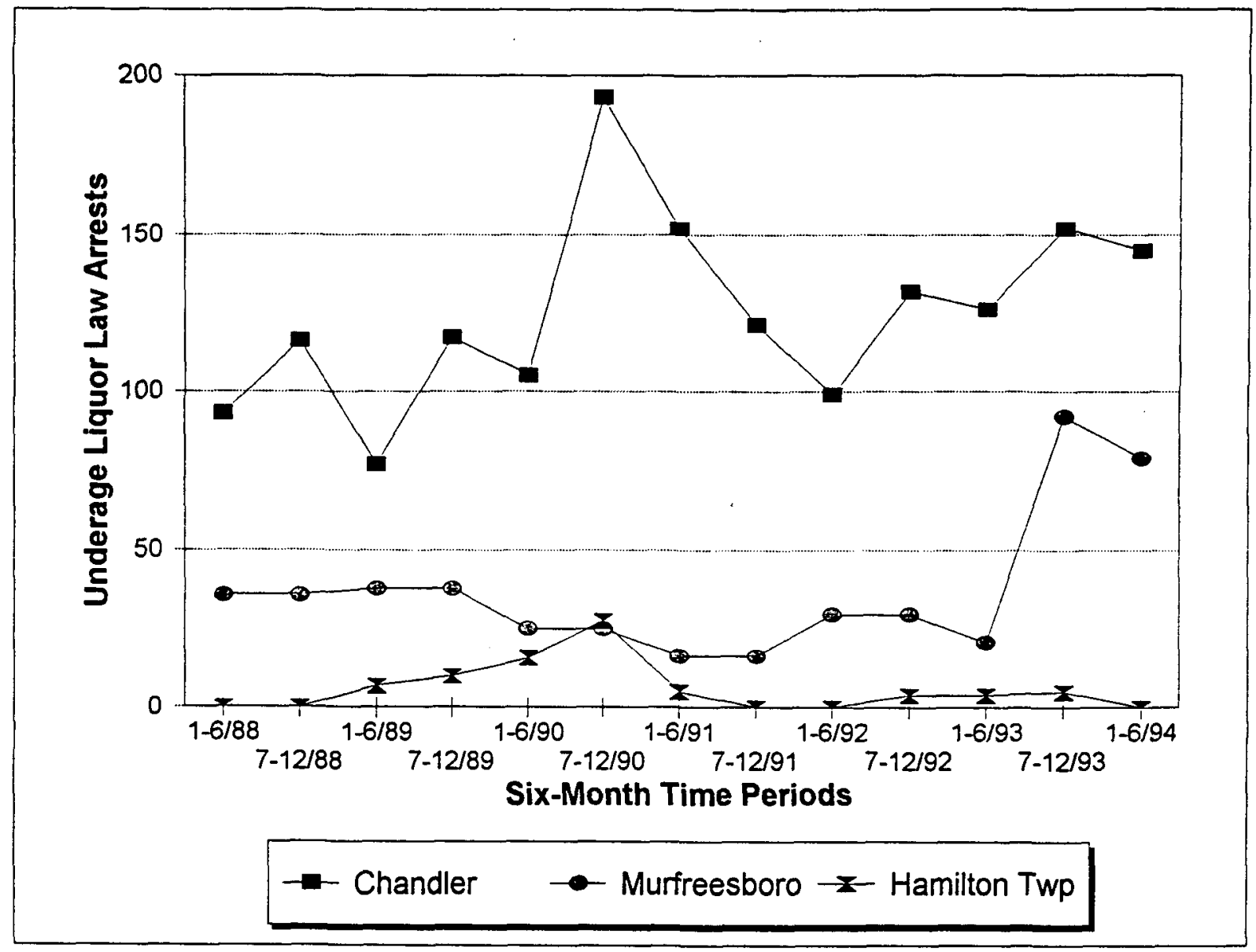

Figure 9. Underage Liquor Law Arrests

\section{Subjective Reactions from Police Officers}

In the process of participating in this test, officers and supervisors developed general opinions and conclusions about the role of passive alcohol sensors in general and about these three specific devices. Observations and recommendations for each specific device are presented first, followed by overall comments and conclusions.

As part of the feedback from the officers and their departments were detailed comments on each of the devices - how they were used, range and limits of their applicability, good points and suggested improvements. In general, even the best devices were disappointing to the officers in terms of their basic accuracy and effectiveness in these field situations. There were major differences perceived between the devices. The comments have been assembled and edited by project staff, and the most important points are summarized below. 


\section{PBA 3000}

Overall, the PBA 3000 was considered perhaps the most sensitive and accurate of the devices tested. This conclusion was primarily based on officers' experiences. It was reinforced by the availability of a direct mode of operation and by the precise-seeming digital readout. Other positive characteristics: As a "computer," its ability to keep memory of test date, time, mode, and results was appreciated. Ability to download directly to a printer or to a PC (for example, to support police record-keeping) was unique to this device and valued. It was seen as relatively sturdy. Although a large device, its shape and features made it more an item of curiosity and less threatening than the P.A.S. III. The lighted readout was visible day and night. The direct mode and its certification by U.S. DOT as a PBT increased its versatility and value, although it was not tested with its optional portable printer as a PBT device (at the time of the study, for example, it was not yet on Arizona's list of approved PBTs).

\section{Police-Preferred Uses}

It was seen as useful for teen parties and liquor law enforcement, for commercial vehicle $.04 \%$ alcohol limit enforcement, for checkpoints, and for day or night use. As a passive sensor, it was judged most useful for discriminating presence or absence of alcohol, much less useful for providing accurate BAC levels. To that end, the software ability to change the display from numerical percentages to Pass-Warning-Fail broad categories was felt to be useful. As a directmode PBT device, it can compete with other devices which only provide PBT capabilities.

\section{How They Operated the PBA 3000}

In operation, the PBA 3000 was usually carried in the officer's hand. Although its beltmounted carrying case was occasionally used, most officers had too many things on their belts already for this option. For nighttime stops, one officer carried the PBA 3000 under one arm, then - when the contact was judged controlled and secure - dropped it into the hand for use. For most officers' traffic stops, though, the PBA 3000 (or either other device) was not used until after the initial evaluation of impairment, including HGN and other field sobriety tests, had been completed. With subjects who were on foot (pedestrians or teens in parties, for example) there was usually a hand available for the device and it could be used at any time during the contact.

\section{Advantages and Disadvantages}

Some officers judged it too large, heavy, and bulky: It was very difficult for bicycle officers to carry it. At least one officer had problems finding a good location in the car so that it would be secure and readily available. The "sonar" distance-measuring feature was both a good point it kept administrations uniform - and a bad one - it made the officer concentrate on the display and often led to delays between when the "sample" button was pressed and when the sampling actually began.

The green light on the end of the device was a distraction to subjects; all three departments disabled the lights (with software commands) for their tests. Also a distraction was 
the noise from the air pump. Subjects often turned their heads away or stopped talking and exhaling when they heard the noise.

The purge cycle, especially after very high readings, was too long in some situations (such as testing groups of teens at parties).

Operation of the PBA 3000 in the field was judged relatively complex. Officers had to find the correct button (it was recommended that the button for passive testing be a unique shape or texture for positive identification by feel), press it, possibly watch the LCD display screen while lining up the device for the test, and push the button again to initiate the test. Also, the pump seemed to lag before starting in some instances, throwing the officer's timing off and compromising the test.

The power switch was occasionally left on, draining batteries; officers suggested an automatic shutoff control.

Other suggested changes were eliminating the green light entirely, putting a mode switch in the mouthpiece socket so that the device could automatically determine if the test was passive or direct, simplifying control sequences for administering tests, revising the location of the exit port so that it would not be blocked when the device was put down (it seemed to extend the purge cycle time when that occurred), providing clearer positive feedback to the operator (e.g.. tactile and/or auditory), and - of course - making it smaller, lighter, and sturdier.

The PBA 3000 exhibited two failures during the test. One was an early failure of the sonar device, which rendered it inoperable in the passive mode (it was repaired). The second appeared to be caused by accidental removal of batteries while the device was turned on. Life Loc is reported to be correcting both ends of this problem: replacing individual AA batteries with a (rechargeable) battery pack, and reprogramming the software so it is not compromised by sudden power loss. Several of the devices had computer-type idiosyncrasies. During the download of information to PCs, several units transmitted noise characters which confused the PC software and contaminated the resulting data files. In several cases, the software command to erase records of past tests in the PBA 3000 memory seemed to fail to operate. Finally, the devices seem to be relatively sturdy, but this test did not subject them to extended periods of routine (mis)handling in normal patrol situations.

\section{P.A.S. III}

\section{Police-Preferred Uses}

The P.A.S. III was judged relatively sensitive to alcohol. The integrated flashlight was intended to provide the ability to substitute this device for the officer's current flashlight, thus increasing capabilities without increasing the number of things to be carried. Some officers felt the flashlight was good enough to use full time, while others felt their existing flashes were too much better to replace. The P.A.S. III was judged, for nighttime use, to be the safest for the officer. 
The unit was judged most applicable to nighttime traffic stops and checkpoints. It was felt to be best at detecting the presence of alcohol, not very accurate or reliable at measuring the level of alcohol. It was good with open containers as well as alcohol on the breath of the driver. Officers also found it quite easily influenced by even slight breezes; they recommended using it only indoors or in other protected settings. By extension, the device should also be applicable for individual teens (i.e., suspected liquor law violations) or commercial vehicle inspections.

The P.A.S. III was not recommended for daytime use, since the flashlight seemed totally out of place at that time and since the LED display was very hard to read in bright light. It was also not recommended for groups of subjects; the P.A.S. III has a very long purge cycle after high positive readings, and this made it too time-consuming to use in testing several subjects at one time.

\section{How They Operated the P.A.S. III}

In traffic stops and other contacts, officers could use the P.A.S. III exactly as they would use their regular flashlight, then deploy it to make the passive test. It fit in the belt holder already used by several officers for their regular flashlights. For car stops, many officers found it awkward to position the device close enough to the driver to get a valid reading, and they found the maneuver inconsistent with using the device as a flashlight. That is, the maneuver was sufficiently distinctive that virtually all drivers knew there was something going on besides shining a light beam. That said, the placement of the sample intake port on the side of the device and the relatively silent air pump were well designed to make the testing as inconspicuous as possiblc.

\section{Advantages and Disadvantages}

Out-of-vehicle testing required that the device be placed up very close to the subject's mouth. This was routinely perceived to be awkward, an invasion of the person's space, and aggressive or threatening. It was also seen as a threat to officer safety, both by bringing him (or her) very close to the subject and by making available to the subject a big, heavy metal club.

The absence of a direct testing mode was felt to be a drawback by most officers, who generally wanted a direct mode available to overcome what they saw as performance shortcomings of passive testing in general. Murfreesboro officers, by contrast, appreciated the lack of a direct mode because of Tennessee law which essentially prohibits PBT use. Their preference, however, would be for a law allowing PBT use coupled with a device having a direct testing mode.

The P.A.S. III is generally quite useful in the controlled setting of a sobriety checkpoint. However, it has a number of perceived design drawbacks that limit its applicability to other situations. Foremost is the control button, which was perceived as making the device confusing to operate and as compromising officer safety. Officers wanted at least two buttons. The first should control the light, and it should have a stay-on-while-button-pressed mode as well as regular on and off modes. The light should respond instantly rather than having a half-second delay before operating. The second button should control the passive sensor much as it is now controlled: push to start (no delay), push again to turn off. The buttons should feel different to 
the touch. The heater control should be separated from the light control, so that decisions about using the light would depend only on functionality and safety factors. It might be possible to integrate heater control into the passive sensor control button, or good design might require a third control button.

Officers like the metal construction of the P.A.S. III, but they want it to have a flat black finish rather than the current shiny finish. The flashlight received mixed reviews. Most officers felt it was an adequate light source and appreciated the ability to focus the beam for near (broad) or distant (narrow) use. Chandler officers much preferred their regular-issue lights, which are brighter, do not have adjustable focus (they are described as being good for both near and distant use without needing adjustment), and are about two-thirds the size.

Officers disliked the display. The primary display was too dim to be readily seen during daylight: Their main concern, however, was that the display did not have BAC numbers next to the LED bars. Even though officers knew that passive alcohol sensors only provide approximately accurate readings because of testing condition variability, they still wanted actual numbers visible to them.

The device was felt to be too big and heavy to be carried by bicycle officers, and motorcycle officers reported it to be too big to fit into their saddlebags.

Battery life was not thoroughly tested in this project, but it was found to be generally adequate as used (i.e., up to several short uses per shift with recharging between shifts). The battery chargers did not always operate smoothly (two failed completely, and the status lights which showed when charging was occurring and was complete were usually unreliable). In limited experience, the separate in-car battery chargers seemed ineffective. PST is reported to be replacing the current battery chargers with integrated ones of new design.

The P.A.S. III also has an unusual problem. On the back end of the unit is a springloaded button-like contact for the charger. If the button is jarred during normal use, it can momentarily cut off all power to the unit and shut off the sensor and the light. This happened once or twice and is another safety issue for officers. With the changeover to integrated chargers, new devices may no longer be subject to this problem.

P.A.S. III units were quite reliable. The only observed problem was that the control button was broken out of one unit when it was accidentally pulled along a sharp surface. The buttons are field-replaceable; thus such problems, which should be rare, should also not keep units out of service.

\section{Mark X}

The Mark X was considered ideal in size, weight, and general appearance. Officers appreciated the fact that it could be kept in a pocket, held alongside a flashlight if need be, tossed aside in emergencies, not used as a weapon against the officer, and whose use was generally not seen as threatening or aggressive. 


\section{Police-Preferred Uses}

When they were able to use it in the direct mode with a mouthpiece, officers were pleased with its accuracy and general useability. Almost every officer, however, found it of little or no value in the passive mode. When using it in the passive mode, officers rarely got any positive readings regardless of how impaired the subject was. Also, they found the instruction pamphlet of no help for how to take passive mode readings.

\section{How They Operated the Mark X}

From an operation standpoint, the Mark $\mathrm{X}$ was simple and straightforward to use. It had a single control switch with just two positions, on/start and off. The LEDs were bright and readable in all light conditions; they showed clearly when the warmup sequence was completed and the device was ready for testing. The colored bar LED display provided general information at a glance, and the BAC level numbers next to the bars were considered very useful in interpreting the meaning of the light display. The audible "beep" when readings reached $.08 \%$ was generally appreciated for letting the officer concentrate on other things besides watching the scale (but one officer had a subject who reacted aggressively when he heard the beeping sound).

\section{Advantages and Disadvantages}

If they could use the Mark X in direct mode, officers would use it in situations where detecting the presence of alcohol was important. This includes zero tolerance and liquor law enforcement for subjects under 21 and commercial vehicle driver inspections. The device clears quickly even after high readings, making it a good choice for teen parties and other situations where groups of people must be tested quickly. The device was also perceived to be adequately accurate (in the direct mode) to provide good general estimates of BAC, that is, as a good supplement to HGN or SFST findings in DWI investigations.

Operational problems with the Mark X were relatively few. However, the on/off switch could be left on with no visible reminder, causing the batteries to drain prematurely. Also, the operation cycle was such that a test could not be initiated quickly or delayed: when the power switch is turned on, the device self-tests for about 10 seconds and then is sensitive to alcohol for about the next minute, after which it stops sampling. It also seemed that the longer and more vigorously subjects blew, the higher their BAC readings climbed.

In general, officers had just one basic suggestion for the Mark X. They would like to see a pump for air sampling added so that it could actively operate in the passive mode. This would make it useful in the sense of the goals of this study. It would also change the operating paradigm of the unit which would allow the shortcomings of the preceding paragraph to be overcome.

Two of the Mark X units failed during the test. They failed in the worst possible manner: Everything about their operation continued to appear normal, but they did not respond at all to the presence of alcohol. 


\section{Overall Comments}

The participating departments and officers had a wide range of opinions about how and whether to use passive alcohol sensors. All agreed they could be useful and safe for officers in sobriety checkpoint operations. They would offer potential benefits in the form of identifying drinking drivers that would otherwise be missed without compromising officer safety. The nature of sobriety checkpoint contacts would also require officers to use the passive sensors at the very beginning of the interview and use the sensor reading as information for the initial release/investigate further decision.

For normal traffic stops where DWI might be suspected, most respondents recommended using the passive sensors sometime during the on-site investigation as another tool like HGN and other standard field sobriety tests. For officer safety, most recommended against using passive sensors as part of the first contact. Because of some uncertainty and concern about how the courts would treat information from the passive sensors, they recommended building an adequate case independent of the passive sensor and using its information to supplement that case.

Passive sensors were seen as potentially valuable at crash investigations, mostly as a way of making preliminary alcohol assessments of subjects who were unable (or unwilling) to actively assist with a PBT device.

Passive sensors were viewed as particularly useful for under-21 subjects, for liquor law violations and also for zero tolerance driving violations (although, for the latter, there seem to be few patrol practices in place which would lead to identifying and stopping violators). Situations include private parties, to which police would have been called while they were in progress, or prom/graduation ceremonies, at which police might have been present as security personnel. Situations would also have included sporting events and concerts. In these instances, the passive sensors would have been used to screen multiple individuals and identify those with any evidence of alcohol consumption. Also for youth, passive sensors were found effective in police presentations in schools, both to demonstrate measurement of alcohol on someone's breath and to emphasize the police department's emphasis on enforcing youth alcohol laws.

Passive sensors were also used and seen to be of benefit on walking or bicycle patrol where potential subjects for testing are youth or adult pedestrians, and in domestic disturbances, where the devices can be useful in alerting the officers to possible alcohol-impairment complications.

For most situations, departments and officers felt that passive-mode alcohol measurements are inaccurate, almost always in the direction of failing to detect alcohol when significant amounts may be present. For this reason, they would prefer to use the devices as true PBTs whenever possible, but to have the passive mode available as a fall-back if only alcohol yes/no detection is required, if time is too short for PBT administration (such as at checkpoints), or if subject cooperation can't be obtained. 
Along with this approach, officers anc ... over general light-bar displays even though they know passive readings such as $.037 \%$ may be too low by $.02 \%, .05 \%$, or more. They wol. $J$ rather have a too-precise reading and use their own judgment about whether it is likely to be accurate. Also, they felt that the precise reading had a positive effect on the subjects. Passive sensor readings were often useful to persuade subjects to talk abol: how much they had drunk rather than continuing to deny drinking at all, and in this case digital displays were more persuasive (even if wrong) than light bar displays.

The participants all understood that some conditions cause the passive sensors to read too high. This was not viewed as much of a problem, though, because it was rare in this study and because the outcome of such an error was not seen a problem. If an inaccurately high reading occurred, it would result in the officer investigating further and, based on other evidence, probably still make the correct decision and take the correct action.

Whether correctly or not, most officers treated the devices as fragile and costly if broken. That is, they were very cautious about what happened to the devices. In instances of conflict with subjects, for example, officers admitted being concerned that the devices not get damaged, although they were not so concerned as to compromise their own safety. The devices are more expensive than most equipment that the officer carries, so such concerns are legitimate. For the concerns to dissipate, it would have to be shown through time and experience that the devices are able to withstand nearly any mistreatment. This study was not long enough, nor were the devices sufficiently resilient, for this to happen.

Finally, all officers and their departments were concerned about whether the passive alcohol sensors could be used without placing the officers at increased risk. This was a central concern, and it directly impacted how and how frequently the devices were used. Because of this and because the sensors readings were believed generally unreliable, many officers were skeptical about the value of passive sensors. A number of instances were cited where, during a passive test, a startled or confused subject grabbed or batted away the passive sensor. In one case, a beligerant pedestrian started to fight with two officers while a passive reading was being attempted. It is the case that using passive sensors can put officers closer to subjects and with less ability to respond quickly. Using passive sensors safely requires careful attention to technique and full attention on the task at hand.

An additional variable in the test was the training and practice the officers received before going into the field with the devices and the support they received during the test. As described above, the actual training officers received was quite short and, especially for the second and third test periods, somewhat informal. The goal was to provide training at about the level that officers would receive in a department with ongoing use of passive alcohol sensors, and it had been judged that less, rather than more, training would be appropriate. Officers described themselves as adequately prepared. However, they also cited instances of failing to operate the devices properly, likely cases of positioning sensors too far from subjects for accurate readings, and of developing their own sensor use techniques over the course of the test periods. That is, the 
training needed to be supplemented with supervised field experience for the officers to be truly proficient with the devices.

At the end of the study, the passive alcohol sensors were distributed to the participating departments according to their preferences. The Mark X units were distributed equally. Each department saw them as valuable for youth enforcement because of their small size, relatively quick recovery period after a positive test, and their effectiveness in the direct mode of testing. The P.A.S. III units were split between Murfreesboro and Hamilton Township. Both appreciated the convenience of the integrated flashlight, their quiet operation, and their ability to detect alcohol in the passive mode. Murfreesboro, because of their laws permitting only a single alcohol test, also valued the fact that the P.A.S. III could only perform passive tests. Chandler felt that their standard issue flashlights were superior to the P.A.S. III light and that officers would not receive any practical benefit from that feature. They preferred the PBA 3000 units for their sensitivity, their ability to function as PBT devices (if approved by Arizona) with direct-mode testing, and the precision and flexibility of the digital display. 


\section{DISCUSSION}

This study placed three current-technology passive alcohol sensors in three police departments in states with zero tolerance laws for youth. All three communities have large numbers of drivers under the age of 21 , and a stated goal of the project was to use the devices in police operations that would maximize the opportunity to enforce youth-alcohol laws - both zero tolerance driving laws and liquor laws such as those addressing underage consumption and open containers in vehicles.

The project sought to evaluate this effort in three ways. First, devices were placed in service in the communities under conditions similar to those which might be expected to occur in a non-experimental, normal situation. Data were collected on actual uses of the devices, subjects on whom the devices were used, and arrest results. Officers also wrote down their significant experiences with and evaluations of the devices, and they participated in focus group discussions to further explore their reactions and recommendations. Second, DWI and liquor law arrest statistics from FBI Uniform Crime Report records were evaluated to determine whether changes in overall arrest rates had occurred which could be attributed to this test program. Third, individual arrest and adjudication records for underage DWI offenders were examined, again to determine if there were changes in the numbers or results of cases which could be attributed to the test program.

Officer data logs did show a number of cases where passive sensors had been used and subjects were arrested for alcohol-related offenses, and officers reported instances in which the passive devices had revealed otherwise undetected alcohol and this resulted in arrests. The youth arrest data, for DWI and for liquor law violations, however, did not reveal patterns of increased arrests associated with the period of sensor use. Also, the individual arrest and adjudication records did not show changes in the ways cases were processed through the justice system associated with the use of the passive alcohol sensors. The lack of impact on arrests is not unreasonable. Each department of more than 100 sworn officers had about six devices to be deployed during the test periods, and when the devices were used they were often used to confirm officer judgments rather than to identify possible alcohol presence that the officer might not otherwise detect.

Although a major emphasis in the study was on zero tolerance and other youth-andalcohol enforcement, the field study emphasized using the passive alcohol sensors in as many situations as possible. To a large extent, the judgment of how usable and valuable the passive sensors were varied based on the setting and on what the passive sensors were asked to do.

Passive sensors were used as part of youth contacts and enforcement. This included nontraffic situations like street encounters and parties, as well as use on underage passengers in vehicles where alcohol was suspected. For youth, the passive sensors were used to identify possible alcohol presence. In domestic disturbance situations as well, the passive sensors were used to identify simply the presence of alcohol. In all of these situations, the presence of a 
measuring device and an objective indication of alcohol gave interactions more structure and moved discussions from denial of drinkii-": to actual quantities consumed.

Passive sensors were also used at crash scenes, including at least one incident when the sensor was used on an unconscious driver as he was being wheeled into an ambulance. Officers were comfortable using one of the passive sensors at a sobriety checkpoint.

The devices were also used in television, newspaper, and personal appearances to publicize the police departments' general emphasis on alcohol-related enforcement, and they were prominently displayed at parties, sports events, and other public activities to deter consumption. In all of these applications, the departments felt that the devices were quite successful.

Most applications of the passive alcohol sensors in this study, however, occurred in the context of traffic stops. For those situations, procedures taught and recommended for the officers emphasized that the sensors should be used at first contact with drivers. This was so that the devices could provide early identification of alcohol presence, perhaps with greater sensitivity than available from the officer's own senses, and provide the officer with the greatest amount of information to guide the rest of the contact. Officers in all sites began by trying to use the recommended procedures, and some officers continued to use them. By the end of the field test, however, most officers used the passive alcohol sensors as a supplement to their usual field sobriety tests. In a typical scenario, vehicles were stopped for driving incidents or patterns which suggested impaired driving, and officers made their initial evaluation of the driver's condition without using the passive device. If they determined that alcohol was likely to be involved, officers conducted their normal field sobriety tests and interview and, in most cases, used the passive alcohol sensor. If the combined weight of evidence supported the conclusion of alcohol impairment, the driver was arrested. Often the passive sensor was used only after an arrest had been made, sometimes only after the subject had been brought to the police department and had completed an evidentiary breath test.

That is, most of the officers did not use information from the passive alcohol sensors as they conducted normal traffic stops. This was reflected in their comments as well as in their logged use of the devices, which was highest during the first test period and declined sharply in the second and third periods. Previous field research (Kiger et al., 1991) has shown that, when procedures like those recommended here are used, passive sensors can be effective in identifying drivers who had consumed alcohol. Most officers in this study, however, gravitated toward procedures which diminished the role of the passive sensors and made it difficult for them to contribute.

Officers did this for several valid reasons. First was their concern for officer safety. As used, these passive devices represented one more item to be held. When used for testing, they required the officers to be close to the subjects and to divert at least part of their attention to the sensors. Some subjects felt threatened by the devices, and some pushed or grabbed at them. While officers grew more comfortable with the devices over time, safety remained a concern, and they often accommodated by developing procedures that did not compromise their sense of security. 
Next, officers questioned the ability of the devices to provide reliable and accurate measures of driver breath alcohol. This was due to a combination of factors. First was that, particularly for traffic stops, the officers wanted the devices to be as reliable and accurate as true PBTs. Second was that, even when used optimally, passive sensors give readings which can be influenced by wind, the cooperation level of the subjects, and other sources of alcohol. Finally, the officers were relatively inexperienced in the use of the devices, and in at least some cases may have used them in ways which reduced their accuracy - such as holding them too far from the subjects (not really possible for the PBA 3000) or making readings when subjects were not cooperating fully.

Also, the officers were not sure how use of the passive sensors might affect the ultimate prosecution of their arrests. In general, their supervisors asked them to make their cases in ways which did not depend on evidence from the passive sensors. For Murfreesboro, because of Tennessee law which permits only a single BAC test, officers were more strongly cautioned to make sure that the passive sensors not be used in a way that could be interpreted as the single permissible test. The result at all sites was that officers were careful to conduct all of their normal screening tests and observations and to keep the passive sensors in the role of supplementary or confirming evidence.

Each of these objections seems to be peripheral rather than central to the effective application of passive alcohol sensors, and each seems to be surmountable. All of them must be addressed before passive alcohol sensors will be used as a regular part of traffic stops. We believe that two additions to the procedures used in this field test would address the objections.

First, the devices must offer positive benefits throughout the arrest-and-adjudication process. That is, prosecutors and judges must be involved. Judges must be aware of the devices and their capabilities, the use of the devices during traffic stops must be accepted by the courts (according to clear guidelines), positive readings must contribute to the evidence, and negative readings must not be able to undermine other evidence of impairment. Prosecutors must also be aware of the devices and their capabilities and be able to successfully argue cases which include evidence from passive alcohol sensors. Ways to do this might include involving judges and prosecutors in decisions about acquiring the devices and providing them with special materials, briefings, or training when the devices are first deployed.

Second, the police can build on the courts' positions to develop guidelines and procedures for the use of passive sensors so they will be useful and effective. The guidelines should include training and supervised practice so that officers understand the purpose, benefits, and limitations of the passive sensors and so that they are proficient in their use. As noted earlier, it may be important to link initial training with supervised field experience. While the passive alcohol sensors are relatively simple to operate, successful use of them in real field situations requires combining the mechanics into effective management of the subject contact.

Summary comments from the police departments were consistent with these conclusions. The departments endorsed the use of the passive alcohol sensors, but they qualified their recommendations in several ways. Devices were expensive, and it was suggested that, for 
departments of $100-200$ officers such as these, three of them might be enough. They should be deployed regularly in patrol or DWI vehicles for use on initial stops and when summoned as backup. They should also be available for youth-related enforcement activities and for commercial vehicle inspections. The department should place them in the hands of officers carefully selected for their competence and their aggressive attitude toward DWI enforcement. The purchase and deployment of the passive alcohol sensors should be done with the involvement, support, and education of the courts and especially the prosecutors. For the passive sensors to produce positive results, it is necessary for them to be known, approved, and accepted at all levels of the judicial system. Prosecutors have to be willing and able to prosecute cases brought with critical evidence supplied by passive sensors, and judges must be willing to convict on such evidence. The police must understand how they can use the passive sensors to build cases that can be successfully prosecuted.

Finally, the devices themselves contributed to the mixed results and recommendations. While each device had strong points, as noted in the Results, each also had weaknesses that prevented any one from being effective in all situations. In part, this is due to the nature of the field test, which encouraged use of the devices in any police contact that might involve alcohol. This included situations where violations involved exceeding BAC limits of $.10 \%, .04 \%$ (for commercial vehicle operators; devices were available for commercial vehicle inspections although not actually used during the field test), $.02 \%, .01 \%$, and $0 \%$ as well as situations in which it simply would have been helpful to officers to know if their subjects had been drinking.

Passive alcohol sensors have not been developed for this full range of applications. Most were originally developed for the purpose of passively estimating a driver's BAC as above or below some limit, typically $.10 \%$. Accuracy in BAC estimation, particularly for BACs near the limit, was at a premium. Achieving accuracy required that the device be held at just the right distance from the driver, capture just the right amount of air, and capture air from breath exhaled typically while the driver was speaking.

Current devices such as those tested here have clearly demonstrated their value for impaired driving enforcement in checkpoint types of police operations. Non-drinking drivers and drivers at low BAC levels can be passed through checkpoints quickly and reliably, thus avoiding the need to unnecessarily detain the public (Jones and Lund, 1986). With these passive devices, drivers at moderate BAC levels are more often detained and eventually arrested (Ferguson et al., 1993; see also Kiger et al., 1991).

\section{Conclusion}

There seem to be three distinct applications for alcohol sensors in the field.

1. Very low level BAC enforcement, such as zero tolerance, youth-oriented liquor laws, or commercial vehicle operators. For sensors in these conditions, accuracy in determining actual BAC level is irrelevant; the only issue is whether or not alcohol is present. If alcohol is present, in any 
quantity, and the suspect is underage, the officer then has reasonable suspicion to proceed with an investigation to determine the source of the alcohol vapors. Passive sensors for these situations could be designed for maximum sensitivity to allow the officer greater latitude in positioning it and starting the sampling. It could, for example, have a stronger pump than the tested models, and it could continue drawing air for a longer period of time - perhaps drawing air until it detected a threshold amount of alcohol or until manually turned off. This kind of device could be used by an officer "sweeping" it in front of the suspect, around the window or interior of the vehicle, to test a number of possible locations for alcohol quickly and unobtrusively. Because these devices are often used to screen many subjects in a short period of time, they should purge or recycle very quickly.

\section{Estimating whether drivers who had been drinking have BACs above or below a DWI} threshold of, say, .08\% or .10\%. This describes the typical sobriety checkpoint situation, but it also applies to the single-officer traffic stops that made up the bulk of the activities in this study. Devices for these situations must be able to provide relatively high accuracy, especially around the DWI threshold, while being quick and easy to use in a way that does not risk officer control of the contact or safety. Their primary application is likely to be at night under poor lighting conditions, but significant applications may occur in daylight or under bright artificial lighting.

3. As a PBT device. That is, used for situations where an accurate BAC measurement is important but the situations are safely under officer control and the subjects are cooperatively participating in the measurement activity. Like many existing PBTs, these devices should be small and portable, should work with the subject blowing into a tube or mouthpiece, and should provide printed records. These are also likely to be used primarily at night, but because of active subject cooperation the officers have more ability to perform the measurements in lighted areas.

Viewed in this way, the devices in this study each provide only a partial solution to police needs. The PBA 3000 is intended to fit second applications and, with an attached printer, the third requirements. It may also be the best suited to the first situation. The P.A.S. III is aimed only at the second application, but could be moderately effective in the first situation. The Mark $\mathrm{X}$, because it lacks an air pump, is suited for the first and second applications only if subjects cooperate by blowing into a mouthpiece.

In conclusion, it is clear that passive alcohol sensors or other portable alcohol sensors can have beneficial application in a wide variety of police operations. Each of the devices tested here has strengths and weaknesses that makes it appropriate for some uses, less appropriate or not at all appropriate for others. Police departments planning to purchase portable alcohol sensors can benefit from clearly identifying their intended applications. 


\section{REFERENCES}

Farina, A.J. 1988. Laboratory Evaluation of Two Passive Alcohol Sensor Devices. National Highway Traffic Safety Administration. NHTSA Technical Report No. DOT-HS-807-394, Washington, DC.

Ferguson, S.A., Wells, J.K, and Lund, A.K 1993. The Role of Passive Alcohol Sensors in Detecting Alcohol-Impaired Drivers at Sobriety Checkpoints. Insurance Institute for Highway Safety, Arlington, VA.

Foss, R.D., Voas, R.B., and Bierness, D.J. 1993. Using a Passive Alcohol Sensor to Detect Legally Intoxicated Drivers. Am J Public Health, 83: 556-560.

Insurance Institute for Highway Safety. 1993. State Law Facts 1993. Insurance Institute for Highway Safety, Arlington, VA.

Jones, I.S., and Lund, A.K. 1986. Detection of alcohol-impaired drivers using a passive alcohol sensor. Journal of Police Science and Administration, 14(2): 153-160.

Kiger, S.M., Lestina, D.C., and Lund, A.K. 1991. Passive Alcohol Sensors in Law Enforcement Screening for Alcohol-Impaired Drivers. Insurance Institute for Highway Safety, Arlington, VA.

Lestina, D.C., and Lund, A.K. 1989. Laboratory Evaluation of Two Passive Alcohol Sensors. Insurance Institute for Highway Safety, Arlington, VA.

Meyers, A.R., Perrine, M.W., and Foss, R.W. 1994. Reliability, Validity, and Internal Consistency of Roadside Measures of Alcohol Use and Related Driving Behavior. (NIAAA: RO1-AA07876) (abstract)

Mothers Against Drunk Driving. Summer, 1994. MADD In Action: Legislative Update. Mothers Against Drunk Driving, Irving, TX.

NHTSA. 1991. Alcohol Involvement in Fatal Traffic Crashes 1989. Mathematical Analysis Division, National Center for Statistics and Analysis. NHTSA Technical Report No. DOT-HS-807-702, Washington, DC.

Preusser, D.F., Ulmer, R.G. and Preusser, C.W. Obstacles to Enforcement of Youthful (Under 21) Impaired Driving. NHTSA Technical Report No. DOT-HS-807-878, Washington, DC.

Preusser, D.F. 1994. Field Evaluation of Passive Alcohol Sensors. Preusser Research Group, Inc., Trumbull, CT. Unpub. 
Voas, R.B. 1983. Laboratory and field tests of a passive alcohol sensing system. Abstracts and Reviews in Alcohol and Driving. 4(3): 3-21.

Voas, R.B., Rhodenizer, A.E., and Lynn, C. 1985. Evaluation of Charlottesville checkpoint operations. Final Report, contract no. DTNH22-83-C-05088. National Highway Traffic Safety Administration, Washington, DC.

Wells, J.K., Preusser, D.F., and Williams, A.F. 1992. Enforcing alcohol-impaired driving and seat belt use laws, Binghamton, NY. Journal of Safety Research, 23: 63-71. 


\section{Appendix \\ Passive Alcohol Sensor Training Materials}




\section{Notes to the Instructor}

The following pages contain lesson plans for training officers in the use of the PBA 3000 Portable Breath Analyzer, the P.A.S. III Passive Alcohol Sensor, and the Mark X Alcohol Checker. Separate lesson plans are included for each of these devices.

The instructor should have knowledge of the operation and maintenance of the passive sensor(s), familiarity with how the passive sensors will be deployed within the department, and an understanding of the objectives and plan for the NHTSA sponsored evaluation of the sensors. Training should be conducted in a classroom setting. A TV monitor and VCR should be available. Prior to the training, the instructor should insure that sufficient copies of the passive sensor's operating instructions and the sensor use logs are available so that each participant can be given this material.

At the conclusion of the training session, participants will:

- Know that the department is participating in an NHTSA sponsored field evaluation of the effectiveness of passive alcohol sensors in the detection of youthful drinking drivers, and will understand the general plan of the evaluation.

- Know how to operate the passive sensor, use it on patrol, and interpret the sensor's readings.

- Understand when they will be assigned a passive sensor and how the sensor will be maintained.

The lesson plans are designed for training prior to deploying the first sensor to be used at a site. When training involves the second or third type of sensor to be introduced, the instructor may wish to briefly review the material in part I, "Overview of Passive Sensors and the Evaluation," and then move directly to the specifics of the particular sensor for which training is to be conducted. This decision should be based on whether (most of) the officers attending have been involved since the beginning of the program. 


\section{Overview of Passive Sensors and the Evaluation Program}

A. Introductions (as appropriate)

B. Evaluation Program

1. NHTSA Sponsored Study of Passive Alcohol Sensors

2. Purpose of the Evaluation

3. Three Passive Sensors

C. Video Tape: "Using the Passive Alcohol Sensor"
Introduce self and attendees as appropriate.

Indicate that the department is participating along with two other departments. These are (as appropriate) the Chandler, Arizona Police Department the Murfreesboro, Tennessee Police Department and the Hamilton Township, New Jersey Police Department.

Indicate that the primary purpose of the evaluation is to determine the effectiveness of passive sensors in the detection of youthful drinking drivers.

Note that three different types of passive sensors will be used, one after the other, and that each will be used for about a two-month period. The PBA 3000 is the first (second or third) one the department will be using.

State that we'll begin by looking at a short video showing how to use a passive sensor. Note that the sensor shown in the video is not one that will be used but that the general techniques are the same.

Show the video tape.

Review the points in the video that 1) passive sensors can be an aid in drinking driver detection but are not a substitute for other investigation techniques and 2) that passive sensors can be valuable in quickly eliminating alcohol from consideration in an investigation. 


\section{Content Outline}

II. Operating the PBA 3000

A. Description of Sensor

B. Description of Operation

C. Demonstration

D. Interpretation of Display Results

\section{Instructor's Notes}

Distribute the passive sensors and operating instructions. If there are more attendees than sensors, group attendees in approximately equal numbers around each sensor.

Hold one of the sensors and point out the control on the front panel, the test result display and the inlet port for drawing the sample. State that the manufacturer indicates that the batteries will last for 500-750 tests.

To be determined pending receipt of units and operating instructions.

Use one of the attendees as a "mock" driver and demonstrate conducting a passive test. Details are to be determined.

To be determined.

State that if the sensor does not record alcohol and there is no evidence to the contrary, it is unlikely that alcohol is present.

State that when the sensor does detect alcohol, its reading is only approximate. The person being tested could have a higher or lower BAC than indicated by the unit. Low readings could be due to test conditions, for example, if the unit is held further from the subject's mouth, if it is windy, etc. High readings could be due to the presence of other sources of alcohol, for example, if other occupants of the vehicle have been drinking. Stress that the sensor is a screening aid not a substitute for officer observation and investigation. 
E. Recovery after Use

F. Practice Use
Indicate that if the unit has detected alcohol, it is ready for another test almost instantly.

Have each attendee perform passive tests using other members of the group as "mock" drivers. Observe and critique as necessary. 
III. Deployment and Logistics
A. Deployment
B. Record Keeping

C. Logistics

IV. Question and Answer Period
Describe how and when the passive sensors will be assigned.

Hand out copies of the sensor log and describe how it should be completed for each test conducted. Stress the importance of accurately completing the $\log$ for each test.

Indicate who will maintain the units and how damage, malfunctions or other problems should be reported.

Ask for questions about the material covered. 


\section{Overview of Passive Sensors and the Evaluation Program}

A. Introductions (as appropriate)

B. Evaluation Program

1. NHTSA Sponsored Study of Passive Alcohol Sensors

2. Purpose of the Evaluation

3. Three Passive Sensors

C. Video Tape: "Using the Passive Alcohol Sensor"
Introduce self and attendees as appropriate.

Indicate that the department is participating along with two other departments. These are (as appropriate) the Chandler, Arizona Police Department the Murfreesboro. Tennessee Police Department and the Hamilton Township, New Jersey Police Department.

Indicate that the primary purpose of the evaluation is to determine the effectiveness of passive sensors in the detection of youthful drinking drivers.

Note that three different types of passive sensors will be used, one after the other, and that each will be used for about a two-month period. The P.A.S. III is the first (second or third) one the department will be using.

State that we'll begin by looking at a short video showing how to use a passive sensor. Note that the sensor shown in the video is not one that will be used but that the general techniques are the same.

Show the video tape.

Review the points in the video that 1) passive sensors can be an aid in drinking driver detection but are not a substitute for other investigation techniques and 2) that passive sensors can be valuable in quickly eliminating alcohol from consideration in an investigation. 
Content Outline

II. Operating the P.A.S. III Passive Alcohol Sensor

A. Description of Sensor

B. Description of Operation

\section{Instructor's Notes}

Distribute the passive sensors and operating instructions. If there are more attendees than sensors, group attendees in approximately equal numbers around each sensor.

Hold one of the sensors and point out the focus ring for adjusting the flashlight beam, the control button for turning the flashlight and the pump on and off, the bar graph display that shows test results, the inlet port used to draw the air sample, the green LED "sample in progress" indicator and the red LED low battery indicator. Indicate that the unit uses rechargeable batteries.

Show the red cone attachment and demonstrate placing it on the P.A.S. State that the cone does not have to be removed to conduct an alcohol test.

Demonstrate turning the flashlight on and off by holding the control button down. Have each attendee practice turning the light on and off.

Indicate that a breath sample is taken by pressing the control button and immediately releasing it. Explain how this action differs from holding the button down to turn the light on and off. Demonstrate and show that the green LED has come on indicating the pump is in operation. Have each attendee practice turning the flashlight on and then drawing an air sample.

Indicate that when the flashlight is on, a fuel cell heater is active. Note that especially in cold weather, the flashlight should be turned on for one minute or more before a sample is drawn. 
C. Demonstration

D. Interpretation of Display Results
Use one of the attendees as a "mock" driver and demonstrate conducting a passive test. Stress that in inlet port should be 5-6 inches from the subject's mouth and that the subject should be talking while the sample is being drawn. Note that the pump runs for about 5 seconds and then turns off automatically.

Indicate that if the sensor detects alcohol, the lights in the bar graph display will begin to come on and reach a peak reading after about 20 seconds showing the approximate alcohol level in the sample. Note that the green and yellow bars are set about $.01 \%$ apart so that when two green and one yellow bars are lighted, the unit is indicating a BAC of approximately $.03 \%$; similarly, when two green and four yellow bars are lighted, the unit is indicating approximately $.06 \%$. Indicate that the red bars are set about $.02 \%$ apart so that when one red bar is lit (in addition to two green and four yellow), the unit is reporting a $\mathrm{BAC}$ of approximately $.08 \%$, two red bars is approximately $.10 \%$, and all bars lighted is $.12 \%$ or more.

State that if the sensor does not record alcohol and there is no evidence to the contrary, it is unlikely that alcohol is present.

State that when the sensor does detect alcohol, its reading is only approximate. The person being tested s. could have a higher or lower BAC than indicated by the unit. Low readings could be due to test conditions, for example, if the unit is held further from the subject's mouth, 
E. Recovery after Use

F. Practice Use if it is windy, etc. High readings could be due to the presence of other sources of alcohol, for example, if other occupants of the vehicle have been drinking. Alcohol in products such as after shave lotion can also be detected by the sensor. Stress that the sensor is a screening aid not a substitute for officer observation and investigation.

Indicate that if the unit has detected alcohol, some time must pass before the unit is ready to conduct another test. The amount of time depends on the amount of alcohol in the prior sample. Indicate that after the unit has detected alcohol, allow a minute or more to go by and then draw a fresh air sample. If bars light, the unit has not yet cleared and the process should be repeated periodically until none of the bars light. Leaving the flashlight turned on will speed the recovery time. Note that in the case of high readings, five minutes or more may be required until the unit is ready for another test.

Note that in cold weather, the P.A.S. III will take longer to reach a peak reading and will take longer to clear. Indicate that in cold weather, the flashiight should be on for several minutes before a test is taken.

Have each attendee perform passive tests using other members of the group as "mock" drivers. Observe and critique as necessary. 
III. Deployment and Logistics
A. Deployment
B. Record Keeping

C. Logistics

IV. Question and Answer Period
Describe how and when the passive sensors will be assigned.

Hand out copies of the sensor log and describe how it should be completed for each test conducted. Stress the importance of accurately completing the $\log$ for each test.

Indicate who will maintain the units and how damage, malfunctions or other problems should be reported.

Ask for questions about the material covered. 


\section{Overview of Passive Sensors and the Evaluation Program}

A. Introductions (as appropriate)

B. Evaluation Program

1. NHTSA Sponsored Study of Passive Alcohol Sensors

2. Purpose of the Evaluation

3. Three Passive Sensors

C. Video Tape: "Using the Passive Alcohol Sensor"
Introduce self and attendees as appropriate.

Indicate that the department is participating along with two other departments. These are (as appropriate) the Chandler, Arizon.1 Police Department the Murfrecstrin. Tennessee Police Department and ith Hamilton Township, New Jerse? Pisins Department.

Indicate that the primary purpun a! the evaluation is to determinc thi effectiveness of passive sensors in ith detection of youthful drinking drises

Note that three different types of passive sensors will be used, onc allict the other, and that each will bx ux.J for about a two-month period. The Mark X is the first (second or third) one the department will be using.

State that we'll begin by looking at a short video showing how to use a passive sensor. Note that the sensor shown in the video is not one that will be used but that the general techniques are the same.

Show the video tape.

Review the points in the video that 1) passive sensors can be an aid in drinking driver detection but are not a substitute for other investigation techniques and 2) that passive sensors can be valuable in quickly eliminating alcohol from consideration in an investigation. 
Content Outlir:

\section{Operating the Mark X Alcohol Checker}

A. Description of Sensor

B. Description of Operation

\section{Instructor's Notes}

Distribute the passive sensors and operating instructions. If there are more attendees than sensors, group attendees in approximately equal numbers around each sensor.

Hold one of the sensors and point wut On/Off switch, the display readout ats on the front, and the battery covct . 's. the back. Demonstrate removal and replacement of the battery covirs

State that the manufacturer cisuni.ul. about 100 tests between batten changes.

Show the opening at the very lir... the sensor and indicate that the M: $X$ could be used with a mouthpuse placed in that opening but that $\|$ n.. not be used that way.

Show the opening at the side (nc.)t ith top) and indicate that this is uhis ... samples are taken into the unit.

Ask a member of each group Io lurn on the Mark X. Ask attendees Io num that all six indicator lights in the display are lighted. State that the sensor is performing a self-test that lasts about 10 seconds. Have attendees observe the display until only the 0 (zero) light is illuminated. Stute that this indicates the sensor is read! to conduct a test.

State that the sensor remains in active mode for about one minute and then all lights on the display turn off. Note that battery power is still being used so the sensor must be turned off between uses. Also note that if a test is not performed within the one minute, the unit must be recycled by turning it off and then back on. 


\section{\begin{tabular}{|c|c|}
\hline Content Outline & Instructor's Notes \\
\hline
\end{tabular}}

C. Demonstration

D. Interpretation of Display Results

E. Recover after Use

F. Practice Use
Use one of the attendees as a "mock" driver and demonstrate conducting a passive test. Highlight the motion involved in waving the sensor back and forth. Caution against allowing smoke to enter unit.

Indicate that if the sensor detects alcohol, the lights in the display will come on to indicate the approximate level in the sample. If a concentration greater than $.08 \%$ is detected, an alarm (a rapid beeping) will sound.

State that if the sensor does not record alcohol and there is no evidence to the contrary, it is unlikely that alcohol is present.

State that when the sensor does detect alcohol, its reading is only approximate. The person being tested could have a high or lower BAC than indicated by the unit. Low readings could be due to test conditions, for example, if it is windy. High readings could be due to the presence of other sources of alcohol, for example, if other occupants in the vehicle have been drinking. Stress that the sensor is a screening aid not a substitute for officer observation and investigation.

Indicate that when the unit has detected alcohol, it is ready for another test almost immediately. Simply turn the sensor off between uses.

Have each attendee perform passive tests using other members of the group as "mock" drivers. Observe and critique as necessary. 
III. Deployment and Logistics
A. Deployment
B. Record Keeping
C. Logistics

IV. Question and Answer Period
Describe how and when the passive sensors will be assigned.

Hand out copies of the sensor log and describe how it should be completed for each test conducted. Stress the importance of accurately completing the $\log$ for each test.

Indicate who will maintain the units and how damage, malfunctions or other problems should be reported.

Ask for questions about the material covered. 